\title{
Groundwater Level Estimation in Northwest Region of Bangladesh Using Hybrid Locally Weighted Linear Regression and Gaussian Process Regression Modeling
}

Ahmed Elbeltagi

Mansoura University and Zhejiang University

Roquia Salam

Begum Rokeya University

Subodh Chandra Pal

The University of Burdwan

Bilel Zerouali

Hassiba Benbouali, University of Chlef

Shamsuddin Shahid

School of Civil Engineering, Universiti Teknologi Malaysia (UTM)

Javed Mallick

King Khalid University

Md. Saiful Islam

Patuakhali Science and Technology University

Abu Reza Md. Towfiqul Islam ( $\nabla$ towfiq_dm@brur.ac.bd)

Begum Rokeya University https://orcid.org/0000-0001-5779-1382

\section{Research Article}

Keywords: Groundwater level estimation, Machine learning, Bangladesh, Locally weighted linear regression, PUK model

Posted Date: January 18th, 2022

DOI: https://doi.org/10.21203/rs.3.rs-1200341/v1

License: (9) (1) This work is licensed under a Creative Commons Attribution 4.0 International License. Read Full License 


\section{Groundwater level estimation in northwest region of Bangladesh using hybrid locally} weighted linear regression and Gaussian process regression modeling

Ahmed Elbeltagi ${ }^{1,2}$, Roquia Salam ${ }^{3}$, Subodh Chandra Pal $^{4}$, Bilel Zerouali $^{5}$, Shamsuddin Shahid ${ }^{6}$, Javed Mallick $^{7 *}$, Md. Saiful Islam ${ }^{8}$, Abu Reza Md. Towfiqul Islam ${ }^{3 *}$

${ }^{1}$ Agricultural Engineering Dept., Faculty of Agriculture, Mansoura University, Mansoura 35516, Egypt

${ }^{2}$ College of Environmental and Resource Sciences, Zhejiang University, Hangzhou 310058, China

${ }^{3}$ Department of Disaster Management, Begum Rokeya University, Rangpur-5400, Bangladesh

${ }^{4}$ Department of Geography, The University of Burdwan, Bardhaman-713104, West Bengal, India

${ }^{5}$ Faculty of Civil Engineering and Architecture, Hassiba Benbouali, University of Chlef, B.P. 78C, Ouled Fares, 02180, Chlef, Algeria

\footnotetext{
${ }^{6}$ Department of Water \& Environmental Engineering, School of Civil Engineering, Universiti Teknologi Malaysia (UTM), 81310 Johor, Malaysia

${ }^{7}$ Department of Civil Engineering, King Khalid University, Abha, Saudi Arabia

${ }^{8}$ Department of Soil Science, Patuakhali Science and Technology University, Dumki, Patuakhali 8602, Bangladesh
}

*Corresponding author: towfiq_dm@brur.ac.bd; jmallick@kku.edu.sa

\section{Abu Reza Md Towfiqul Islam, PhD}

Javed Mallick, PhD

ORCID: 0000-0001-5779-1382 
Abstract

33 The knowledge about the role of the underlying variables on groundwater level (GWL)

34 fluctuation at local scale in the drought-prone urban areas of Bangladesh is still not explored. To 35 better insight into the relative contribution of underlying factors on GWL fluctuation, this study 36 proposed a novel hybrid ensemble modeling framework based on locally weighted linear 37 regression (LWLR) and four Gaussian Process Regressions (GPRs) e.g., poly kernel, Pearson universal kernel (PUK), radian basis function (RBF) and normalized poly kernel. The proposed 39 framework has employed to predict GWL at six wells in the drought-prone local areas of Northwestern urban region of Bangladesh, where GWL is declining rapidly. The rainfall, temperature 41 (Tave), soil moisture (SM), normalized difference vegetation index (NDVI), Indian Ocean 42 Dipole (IOD), Southern Oscillation Index (SOI), Nina3.4, and population growth rate for the period 1993-2017 were utilized as inputs to developed GWL models. The best input combination 44 was explored using the best subset regression model and sensitivity analysis, and the optimal 45 input combination was applied in LWLR and GPRs to estimate monthly GWL fluctuation. The 46 hybrid LWLR-GPR-PUK model, on average, improves the prediction accuracy from 10 to $50 \%$ 47 during the training stage and $20-70 \%$ during the testing stage compared to other models. The 48 proposed modeling approach can act as a promising substitute tool to estimate GWL fluctuation, 49 especially in drought-prone local areas in urban regions where groundwater data scarcity hinders 50 the physical law-based model development.

51 Keywords: Groundwater level estimation, Machine learning, Bangladesh, Locally weighted 52 linear regression, PUK model 


\section{1. Introduction}

56 Sustainable use of groundwater is now a prime concern to the decision-makers and practitioners

57 worldwide, especially in an agrarian-based developing country like Bangladesh (Hasanuzzaman

58 et al. 2017). In the recent years, hydro-climatic variabilities, fast population growth and over-

59 exploitation have adversely affected this precious resource in many regions across the globe

60 (Salam et al. 2020a; Wu et al. 2021). This is particularly true for Bangladesh, where water

61 demand is drastically increased (Islam et al. 2021a). As a result, groundwater level (GWL) is

62 declining rapidly, thus raising the water stress. The local areas are not free from this problem too.

63 Reliable local level groundwater fluctuation data in time and space is the primary prerequisite of

64 getting the clear insight about the contemporary condition of groundwater fluctuation at local

65 areas which is very essential to act accordingly to avoid extreme events arising from the

66 withdrawal of gwoundwater at local areas. Therefore, prediction of local level GWL is essential

67 for the water-stressed drought-prone areas.

68 The physically-based models are generally used to simulate groundwater quality and quantity

69 (Hosono et al. 2019). However, the traditional groundwater models such as MODFLOW

70 (Harbaugh et al. 2000), HYDRUS (Šimůnek et al. 2003) need extensive data, parameters and

71 sufficient experience. The high cost and long computational time are also other issues of

72 groundwater simulation using traditional models. To overcome these shortcomings, scientists

73 adopted alternative techniques in recent decades, e.g., data-driven (statistical and soft computing

74 machine learning (ML) algorithm) surrogate of the physically-based traditional models for

75 predicting GWL (Rahman et al. 2020).

76 The data-driven soft computing technique does not depend on the underlying complicated

77 hydrological process. Instead, it solely depends on the statistical associations between 
explanatory and response parameters. The soft computing models commonly used in GWL

79 prediction include Artificial Neural Network (ANN) (Mirarabi et al. 2019), Support Vector

80 Machine (SVM) (Tang et al. 2019), Adaptive-Network-based Fuzzy Inference System (ANFIS)

81 (Gong et al., 2018), Extreme Learning Machine (ELM) (Alizamir et al., 2018), Random Forest

82 (RF) (Koch et al. 2019) and M5 tree (M5P) model (Kisi 2015). Despite their success in GWL

83 modelling efficiently with less data, these techniques suffer from some shortcomings. For

84 instance, the ANN also exhibits high sensitivity to the trained data, overfitting problem and

85 dependence on hidden neurons and poor forecasting (Shiri et al. 2020). The performance of SVM

86 depends on the optimal selection of kernel functions (Sheikh Khozani et al. 2019). The tree-

87 based models like the Random Tree (RT), M5P tree, and Reduced Error Pruning Tree (REPTree)

88 have weak predictability, limiting their use in robust modelling of GWL (Song et al. 2019).

89 Recently, novel hybrid ensemble algorithms have been used to overcome the difficulties of 90 standalone data-driven algorithms in GWL prediction (Yadav et al. 2020; Wu et al. 2021;

91 Mallick et al. 2021a). Several recent studies employed hybrid ensemble models for different

92 hydro-meteorological applications (Yadav et al., 2020; Sharafati et al. 2020; Mallick et al.

93 2021b). The studies showed promising outcomes using hybrid ensemble models.

94 The highly nonlinear association of GWL with its predictive variables can be explained using a 95 local modeling approach, such as Locally Weighted Linear Regression (LWLR). The main 96 advantage of LWLR is that its training stage occurs at the prediction phase to enhance prediction 97 precision (Cleveland and Devlin 1988). Few studies have applied this novel LWLR algorithm 98 for solving prediction problem (Jamei and Ahmadianfar 2019; Ahmadianfar et al. 2020; Huang 99 et al. 2020). However, it has not been used so far for GWL prediction. 
The surrogate models, namely Gaussian Processes Regression (GPR), are among the most potent prediction approaches. The GRP showed excellent performances in hydrological modelling, including forecasting groundwater depth fluctuations (Kumar et al. 2020), groundwater salinity prediction (Lal and Datta 2020), etc. The LWLR has a fast convergence characteristic, but it needs adjustment of many parameters requiring high computational cost. Therefore, high precision at less computation cost is achievable by hybridizing GRP with LWLR. However, hybridizing GRP with LWLR model application in GWL modelling and prediction has not been extensively explored yet in exisitng literature.

The precision of data-driven prediction models significantly relies on the input datasets utilized (Sahoo et al. 2017). Precipitation, evapotranspiration, surface temperature, and pumping rate are some of the most evident inputs of GWL prediction model (Wunsch et al. 2018). Furthermore, GWL is also partly influenced by intra-annual to decadal climate variability and change, hydrometeorological factors, soil moisture, urbanization and land-use/land-cover (Kuss and Gurdak 2014).

Groundwater management planning (GMP) is essential to control GWL drop. However, the aquifer system is dynamic and different from location to location depending on several surficial and aquifer related factors. No matter how close the wells are, the dynamic nature of the aquifer system has been made it inconvenient to generalize an idea about the GWL fluctuation of any region by analyzing data of few wells or one well. For this reason, for assessing regional level GWL fluctuation, it needs considering all the wells situated in any specific region. But, in a country like Bangladesh, it is very difficult to collect data from all wells of any region due to it will consume huge money, formalities, and time. This leads the authors to choose only 2 wells from each district ( 6 wells in total) to predict the local level GWL fluctuation (instead of regional GWL fluctuation) that would give knowledge for a systematic understanding of the local level GWL fluctuation in drought-prone 
124 urban groundwater aquifer influenced by climatological, hydro-meteorological, and human-

125 induced factors. This work has two objectives. First, to estimate the local level monthly GWL

126 using novel hybrid soft computing models in three urban districts of North-western Bangladesh.

127 Second, to determine the best input combination using sensitivity analysis for better prediction 128 accuracy.

129 2. Data and method

$130 \quad 2.1$ Study area description

131 The northern part of the North-western region of Bangladesh covers $23.5 \%\left(34,515 \mathrm{~km}^{2}\right)$ of the 132 country's total land. The region consists of 16 administrative districts, of which Dinajpur, 133 Nilphamari and Rangpur districts were selected for this study. Total 6 wells from the 3 districts 134 (2 wells from each district) are considered for this research (Figure 1). The study area, bounded 135 by $23^{\circ} 47^{\prime} \mathrm{N}$ to $25^{\circ} 50^{\prime} \mathrm{N}$ latitude and $88^{\circ} 01^{\prime} \mathrm{E}$ to $89^{\circ} 48^{\prime} \mathrm{E}$ longitude, is located on the West of the 137 western region is about 61.5 million, with a density of $930 / \mathrm{km}^{2}$. The North-western region is networked by several rivers and underlined by distinct oxidized red soils and sediments of Plio-

139 Pleistocene and Holocene ages (Rashid et al. 2015; Das 2021). The elevation of the channel140 floodplain complexes is about 8-23 m above mean sea level (AMSL), and the Himalayan 141 piedmont plain is approximately 30-45 $\mathrm{m}$ AMSL. There is a wide variation in the sub-surface 142 lithology in the North-western region (Figure 2). Two types of aquifers are found in the North143 western region of Bangladesh which are: i) semi-confined shallow aquifer which is found just 144 below the top soil spreading from $10-35 \mathrm{~m}$, ii) lower shallow aquifer spreading from 20-70 m 145 and is made of sand (coarse-medium grained), silt and fine sediment. Nearly $82 \%$ of annual 146 rainfall in the area happen during May-October (rainy monsoon period), and only $18 \%$ of rain 
147 occurs during November-April (dry season) (Ghose et al. 2021). It has a diverse monsoon 148 season, with an annual mean temperature ranged from $19^{\circ} \mathrm{C}$ in January to $31^{\circ} \mathrm{C}$ in August with a 149 mean of $26^{\circ} \mathrm{C}$ (Das and Islam 2021). The notable changes in several monthly climatic parameters 150 confirm that the climate of the North-western region is continuously changing (Salam et al., 151 2020b).

152 


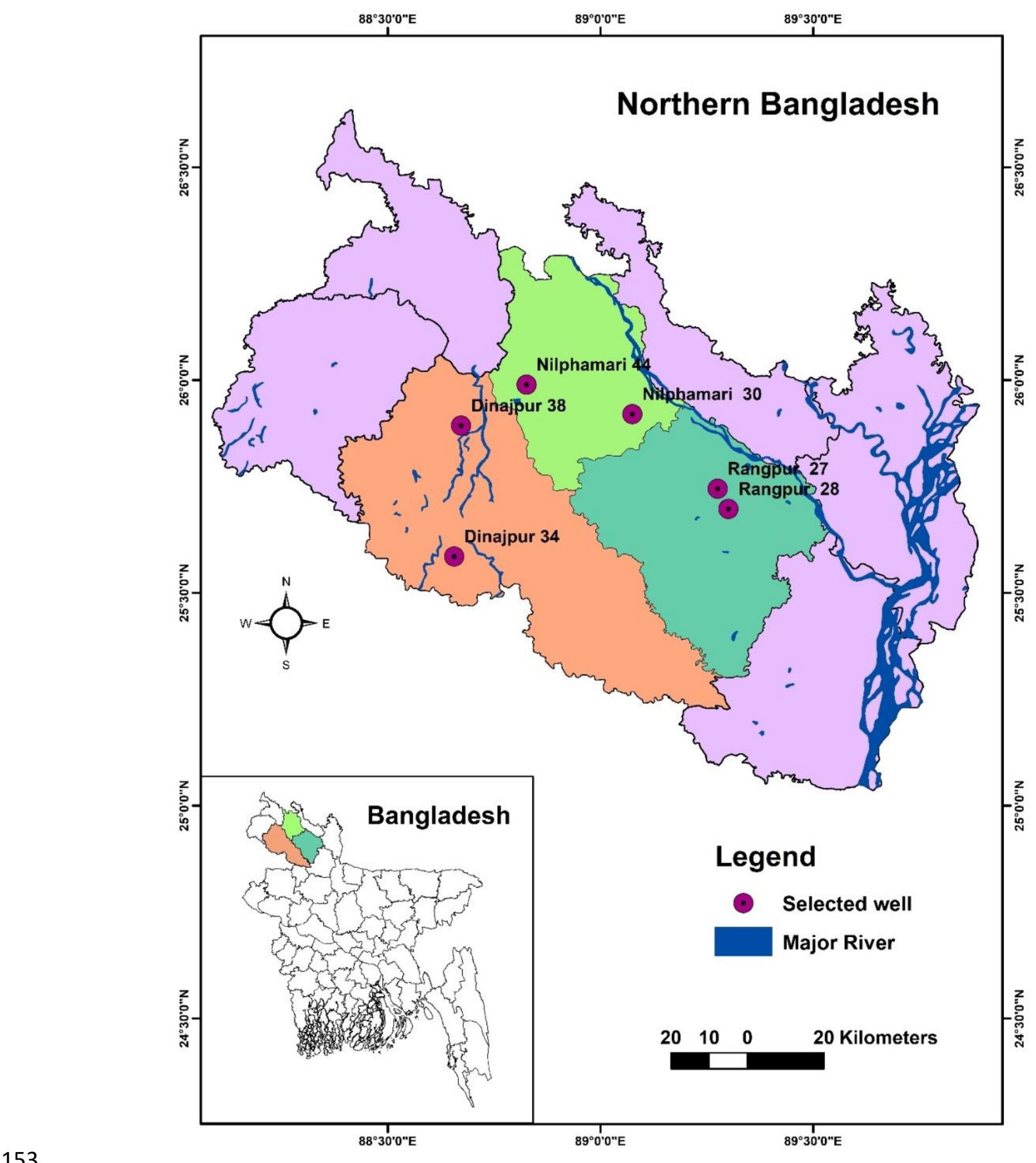

Figure 1: Map showing the northwest region of Bangladesh 


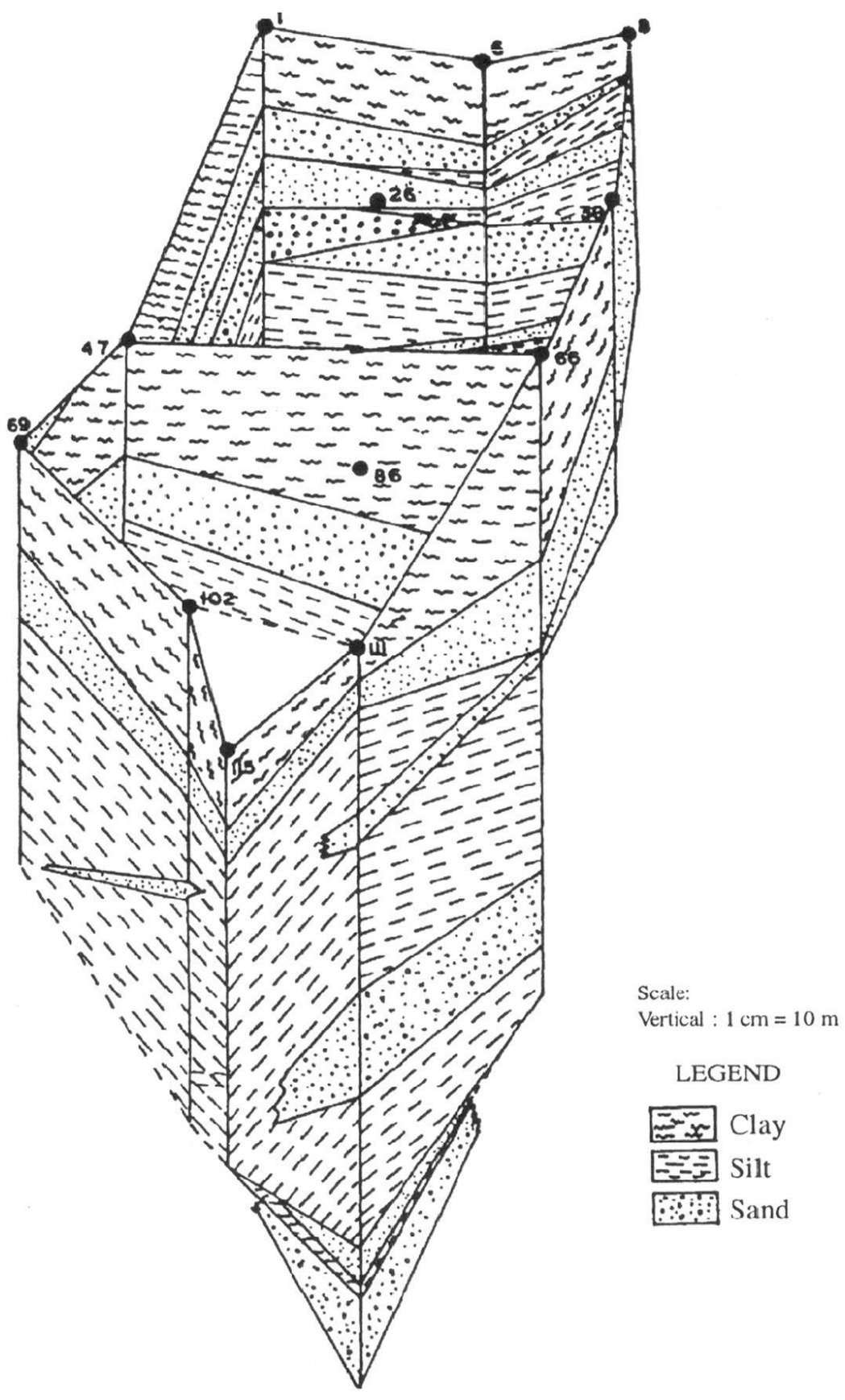

156 Figure 2: Stratigraphic panel diagram of the North-western region of Bangladesh (Source: Jahan 157 et al. 2007)

\subsection{Data}

159 The present study used several datasets from different sources for predicting local level GWL

160 fluctuation. The daily (which then converted to monthly) rainfall and average temperature;

161 monthly soil moisture (SM); Indian Ocean Dipole (IOD), Southern Oscillation Index (SOI) and 
162 Nina; population growth; MODIS Normalized Difference Vegetation Index (NDVI) data for 163 Rangpur, Nilphamari and Dinajpur meteorological stations were collected from Bangladesh 164 Meteorological Department (BMD); Bangladesh Water Development Board (BWDB); Food and 165 Agricultural Organization (FAO); National Oceanic and Atmospheric Association (NOAA) 166 Climate Prediction Center (CPC); Bangladesh Bureau of Statistics; National Aeronautics and 167 Space Administration (NASA), respectively and monthly GWL (m) data for 6 selected wells 168 from the Bangladesh Water Development Board (BWDB). The MODIS data was collected in 169 Network Common Data Form (NetCDF) format and then converted to excel format. All the data 170 were collected for the period 1993-2017.

183 where $f(x)$ is the regression.

184 For "y" observation, the Gaussian noise function is:

$185 y=f(x)+\varepsilon$ 
$186 \varepsilon \approx N\left(0, \sigma_{f}^{2}\right)$

187 where $\varepsilon$ is the noise of normal distribution function with $\mathrm{N}\left(0, \sigma_{f}^{2}\right)$. The new way for noise 188 combination in covariance function $k(\mathrm{x}, x)$, described according to Akbari et al. (2019) as follow:

$189 k\left(x, x^{\prime}\right)=\sigma_{f}^{2} \exp \left[\frac{-\left(x, x^{\prime}\right)^{2}}{2 \tau^{2}}\right]+\sigma_{n}^{2} \delta(x, x)$

$190 \delta(x, x)$ is the Kronecker delta function, and $n$ is the observations of $\mathrm{y}$. The choice of the appropriate 191 kernel can give a good map of the input series for processing inputs in high dimensional feature 192 space (Kumar et al. 2019). The most important kernels are described below.

193 The Poly kernel represents the similarity of vectors in a feature space allowing learning of 194 nonlinear models.

$195 k\left(x_{i}, x\right)=\left(\left(x_{i}, x\right)+1\right)^{d}$

196 The normalized kernel version can reduce the sparse data and allow building a better model. It 197 can be expressed as:

$198 \quad k\left(x_{i}, x\right)=K\left(x_{i}, x\right) / \sqrt{K\left(x_{i}, x_{i}\right) K(x, x)}$

199 Radial Basis Function (RBF) also known as "squared exponential", is a stationary kernel given 200 by the equation (7).

$201 \quad k\left(x_{i}, x\right)=e^{-\gamma\left|x_{i}-x\right|^{2}}$

202 Pearson (1895) proposed the Pearson Universal Kernel (PUK) as an alternative to the generic 203 kernel function for curve fitting. The mathematical description of the kernel is as below:

$204 k\left(x_{i}, x\right)=\left(1 /\left[1+\left(2{\sqrt{\left\|x_{i}-x\right\|}}^{2}{\sqrt{\left.2^{(1 / \omega)}-1 / \sigma\right)^{2}}}^{\omega}\right.\right.\right.$ 


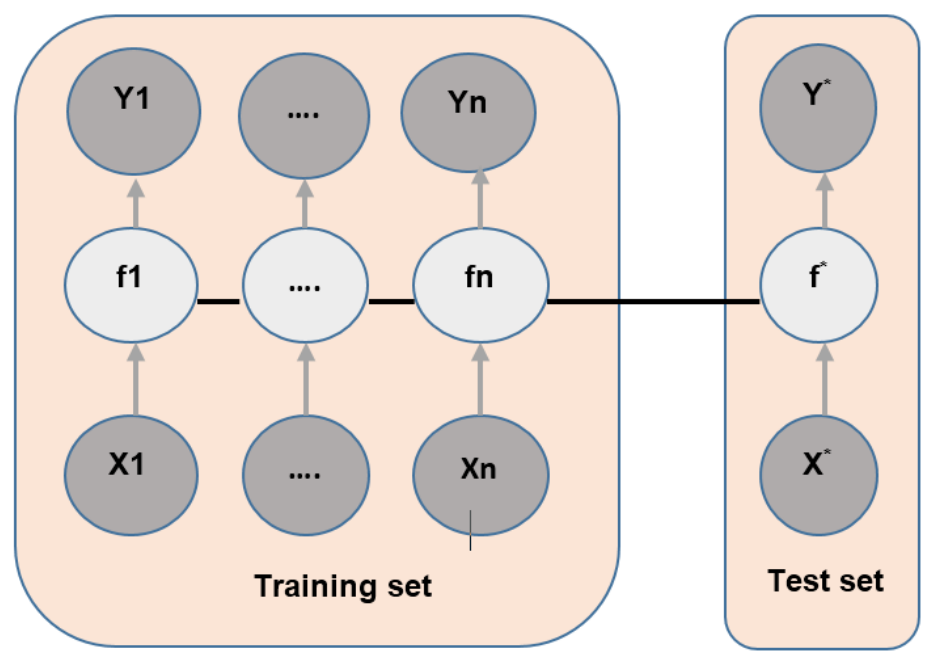

\subsubsection{Locally Weighted Linear Regression (LWLR)}

Atkeson et al. (1997) first proposed the LWLR, a classical non-parametric regression approach. LWLR is one of the most classical approaches used in statistical and ML fields. It takes the basic conception of multiple linear regression (MLR). The LWLR covers the drawback of the MLR, which under-fits the data and negatively impacts the prediction process, especially in complex problems

212 (Jamei et al. 2020). It uses the Weight function to define the relationship between the predictand and 213 the training dataset (Ahmadianfar et al. 2020). The loss function $F(\vartheta)$, explained by equation (4), is 214 used to find the learning model $\vartheta$. One of the major advantages of the LWLR is the making testing 215 phase in parallel with prediction steps, which can provide the lowest mean-squared error (MSE) in 216 prediction.

$217 \quad F(\vartheta)=\sum_{i=1}^{n} w_{i}\left(y_{i}-\vartheta^{T} x_{i}\right)^{2}$

218 The Gaussian kernel function is written as: 
$219 W(i)=\exp \left(-\frac{\left(x_{i}-x\right)^{2}}{2 k^{2}}\right)$

220 where, $W$ is a weight matrix used to decrease the function distance between the estimated data

221 corresponds to the test or request point, $x_{i}$ refers to the $\mathrm{i}^{\text {th }}$ training example point, $k$ represents

222 the bandwidth parameter that can be modified and adjusted to select the width of the kernel for

223 the best distance between the request and training point. According to Huang et al. (2020), the

224 LWLR kernel function is symmetric. Therefore, it is better to distribute the sample points within

225 the dotted circle area. If the solid circle area A is the training sample, some sample points lost in 226 the solid circle area of B (Figure 4).

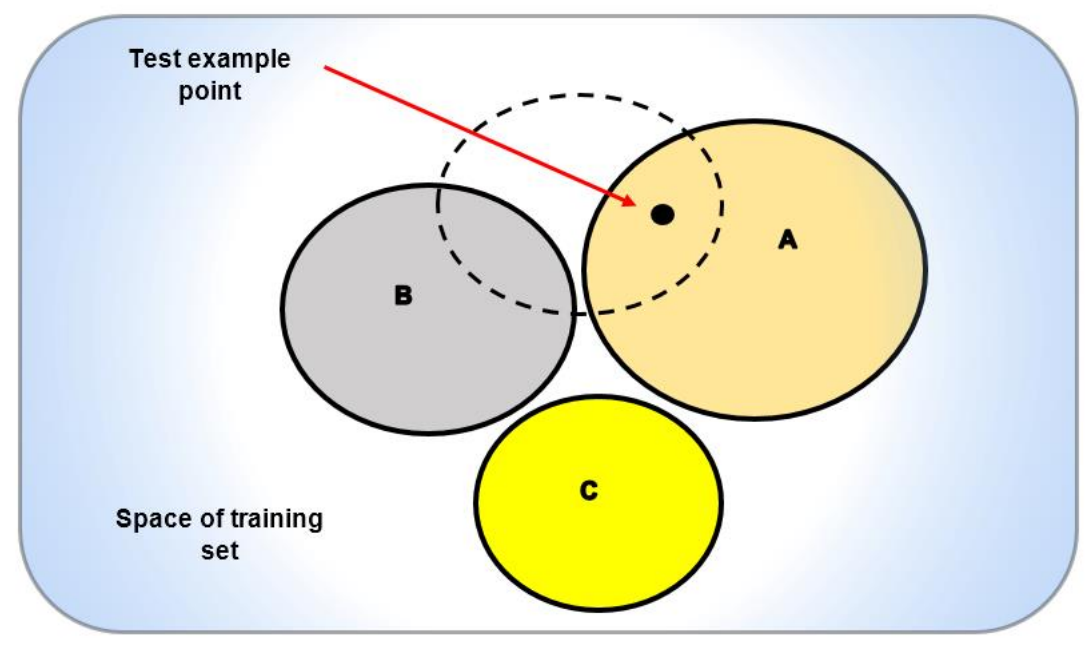




\section{$232 \quad 2.4$ Statistical error measures}

233 Observed and modeled GWL data were compared for the study period to evaluate the accuracy

234 of the models using five statistical indices: Root Mean Square Error (RMSE), Mean Absolute 235 Error (MAE), Relative Absolute Error (RAE), Root Relative Squared Error (RRSE), and 236 Correlation Coefficient (CC). The equations of the statistical indices are noted below.

$237 \quad \mathrm{RMSE}=\sqrt{\frac{1}{\mathrm{~N}} \sum_{i=1}^{N}\left(G W L_{A}^{i}-G W L_{p}^{i}\right)^{2}}$

$238 M A E=\frac{1}{\mathrm{~N}} \sum_{i=1}^{N}\left|G W L_{p}^{i}-G W L_{A}^{i}\right|$

$239 \quad \mathrm{RAE}=\left|\frac{G W L_{A}^{i}-G W L_{P}^{i}}{G W L_{P}^{i}}\right| \times 100$

240

$\operatorname{RRSE}=\frac{\sqrt{\sum_{i=1}^{N}\left(G W L_{P}^{i}-G W L_{A}^{i}\right)^{2}}}{\sqrt{\sum_{i=1}^{N}\left(G W L_{A}^{i}-G W L^{-}\right)^{2}}}$

$241 \quad C C=\sqrt{1-\frac{\sum_{i=1}^{N}\left(G W L_{P}^{i}-G W L_{A}^{i}\right)^{2}}{\sum_{i=1}^{N}\left(G W L^{-}-G W L_{A}^{i}\right)^{2}}}$

$242 G W L_{A}^{\tilde{i}}$ is the observed or actual GWL, $G W L_{p}^{\tilde{i}}$ is the simulated GWL, $G W L^{-}$is the mean of

243 observed GWL, and $\mathrm{N}$ is the total number of data points.

\section{$244 \quad 2.5$ Model optimization}

245 There is no ideal consensus on data division. The present study used data from 1993-2017. The 246 first 76\% of data (1993-2011) were used for training, and the rest of the 24\% data (2012-2017)

247 were used for testing. The nine models developed in this study were first optimized. Different 248 mechanisms are available for optimizing or tuning model hyperparameters. The present study 249 utilized the Grid search technique for optimizing model parameters. The optimized values of 

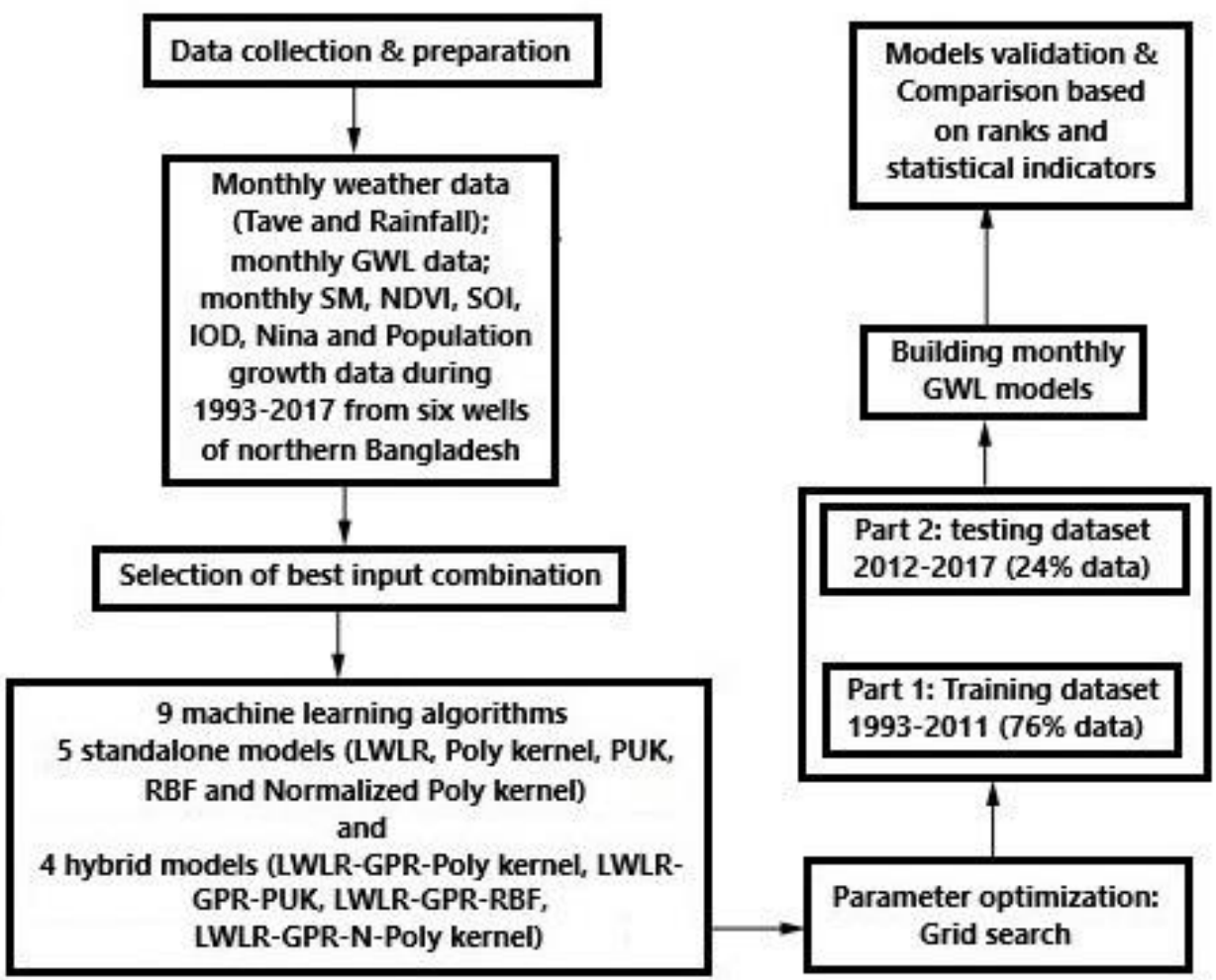

Figure 5: Methodological flowcharts for the proposed novel hybrid modeling framework groundwater level prediction

Model name

Locally weighted linear

regression (LWLR)

Gaussian Process

Regression $($ GPR) based $\quad 1$; Filter type $=$ Normalize training data; Cache size $=250000$

\section{Description of parameters}

Batch size-100, KNN=0, Nearest neighbor search

algorithm= linear NN

Kernel=Normalized Poly; Batch size-100, Noise $=1$, Seed $=$ 
on four kernels
Kernel $=$ Poly; Batch size-100, Noise $=1$, Seed $=1$; Filter

type $=$ Normalize training data Cache size $=250000$

Kernel= PUK; Batch size-100, Noise $=1$, Seed $=1$; Filter

type $=$ Normalize training data; Cache size $=250000$; Omega

$=1$, Sigma $=1$

Kernel $=$ RBF; Batch size-100, Noise $=1$, Seed $=1$; Filter

type $=$ Normalize training data; Cache size $=250000 ;$ Gamma $=0.01$
260

261

262

263

264

\section{Results}

\subsection{Multicollinearity assessment and descriptive statistics of conditioning variables}

The present study performed a multicollinearity assessment for checking whether the variables are valid enough to build any model for predicting GWL (Table 2). Variance inflation factor (VIF) and tolerance statistics are the common methods used for detecting multicollinearity. The VIF of a variable close to 1 indicates no correlation existed with other variables. SOI and NINA at all stations showed a VIF higher than 2 (less than 2.30), meaning less multicollinearity effects that do not affect the results (Table 2). Soil moisture is mainly affected by rainfall and temperate affects rainfall. So, these variables may have VIF more than 1 which is expected. Rainfall (Rangpur and Nilphamari, VIF is very close to 2 for Dinajpur) and SM (Nilphamari, VIF is very close to 2 for Dinajpur and Rangpur) showed a VIF higher than 2, which cannot much affect the results. The VIFs of the rest of the variables at all stations were less than 2 (close to 1), indicating that they are free from the multicollinearity effect (Table 2). The standard error (SE) of mean, standard deviation (StDev), minimum, first quartile (Q1), middle number (Median), third quartile (Q3) and maximum values of the selected variables during both training and testing period are given in Table 3. 
Table 2: Multicollinearity statistics of conditioning variables

\begin{tabular}{l|cc|cc|cc}
\hline \multirow{2}{*}{ Variables } & \multicolumn{5}{c}{ Collinearity Statistics } \\
\cline { 2 - 7 } & \multicolumn{2}{|c}{ Rangpur } & \multicolumn{2}{c}{ Nilphamari } & \multicolumn{2}{c}{ Dinajpur } \\
\cline { 2 - 7 } & Tolerance & VIF & Tolerance & VIF & Tolerance & VIF \\
\hline Rainfall & 0.489 & 2.046 & 0.454 & 2.202 & 0.591 & 1.693 \\
Tave & 0.927 & 1.078 & 0.531 & 1.882 & 0.947 & 1.055 \\
NDVI & 0.924 & 1.082 & 0.92 & 1.087 & 0.944 & 1.059 \\
IOD & 0.821 & 1.218 & 0.847 & 1.18 & 0.837 & 1.195 \\
SOI & 0.478 & 2.094 & 0.469 & 2.132 & 0.47 & 2.13 \\
NINA & 0.429 & 2.333 & 0.449 & 2.229 & 0.429 & 2.33 \\
SM & 0.514 & 1.946 & 0.483 & 2.073 & 0.6 & 1.665 \\
Population Growth & 0.981 & 1.02 & 0.97 & 1.031 & 0.978 & 1.023 \\
\hline
\end{tabular}

279 Table 3: Descriptive statistics of the data during the training (A: 1993-2011) and testing period

280 (B: 2012-2017) in Rangpur

\begin{tabular}{|c|c|c|c|c|c|c|c|c|}
\hline Variable & Mean & SE Mean & StDev & Minimum & Q1 & Median & Q3 & Maximum \\
\hline A. Training & & & & \multicolumn{5}{|l|}{ Rangpur } \\
\hline Rainfall & 187.4 & 13.80 & 208.0 & 0.0 & 6.3 & 109.0 & 336.8 & 913.0 \\
\hline Tave & 24.56 & 0.288 & 4.347 & 13.9 & 21.925 & 26.400 & 28.300 & 29.700 \\
\hline NDVI & 0.197 & 0.005 & 0.074 & 0.047 & 0.138 & 0.1790 & 0.252 & 0.412 \\
\hline IOD & -0.014 & 0.024 & 0.361 & -0.887 & -0.251 & -0.027 & 0.163 & 1.473 \\
\hline SOI & -0.004 & 0.746 & 11.264 & -28.6 & -7.875 & 0.200 & 8.825 & 27.100 \\
\hline NINA & -0.078 & 0.057 & 0.862 & -1.79 & -0.720 & -0.115 & 0.450 & 2.420 \\
\hline SM & 118.86 & 3.97 & 59.89 & 26.00 & 54.25 & 129.00 & 179.00 & 179.00 \\
\hline Population Growth & 2.039 & 0.025 & 0.384 & 1.06 & 1.830 & 1.9500 & 2.260 & 4.1500 \\
\hline \multicolumn{9}{|l|}{ B. Testing } \\
\hline Rainfall & 176.1 & 24.4 & 207.3 & 0.0 & 2.0 & 112.5 & 309.3 & 784.0 \\
\hline Tave & 32.05 & 3.90 & 33.05 & 15.00 & 25.63 & 29.10 & 31.67 & 306.00 \\
\hline NDVI & 0.19400 & 0.009 & 0.072 & 0.045 & 0.141 & 0.183 & 0.248 & 0.380 \\
\hline IOD & 0.0643 & 0.033 & 0.283 & -0.486 & -0.151 & 0.041 & 0.311 & 0.749 \\
\hline SOI & -2.00 & 1.04 & 8.82 & -22.00 & -7.75 & -1.35 & 4.13 & 13.90 \\
\hline NINA & 0.277 & 0.101 & 0.856 & -0.930 & -0.320 & 0.095 & 0.547 & 2.570 \\
\hline SM & 114.24 & 7.26 & 61.58 & 25.00 & 47.00 & 125.00 & 179.00 & 179.00 \\
\hline Population Growth & 2.784 & 0.107 & 0.911 & 1.620 & 2.120 & 2.510 & 3.217 & 5.250 \\
\hline A. Training & & & & \multicolumn{5}{|c|}{ Nilphamari } \\
\hline Rainfall & 186.2 & 14.6 & 221.0 & 0.0 & 4.0 & 82.5 & 306.0 & 951.0 \\
\hline SM & 123.77 & 4.21 & 63.56 & 26.00 & 57.00 & 133.50 & 191.00 & 191.00 \\
\hline NDVI & 0.173 & 0.003 & 0.047 & 0.06560 & 0.14050 & 0.170 & 0.202 & 0.345 \\
\hline IOD & -0.014 & 0.024 & 0.361 & -0.8867 & -0.2510 & -0.027 & 0.1635 & 1.473 \\
\hline SOI & -0.004 & 0.746 & 11.264 & -28.600 & -7.875 & 0.200 & 8.825 & 27.100 \\
\hline NINA & -0.078 & 0.057 & 0.862 & -1.7900 & -0.7200 & -0.115 & 0.4500 & 2.4200 \\
\hline Population Growth & 2.039 & 0.025 & 0.384 & 1.0600 & 1.8300 & 1.9500 & 2.2600 & 4.1500 \\
\hline B. Testing & & & & & & & & \\
\hline
\end{tabular}




\begin{tabular}{l|llllllll}
\hline Rainfall & 151.1 & 20.9 & 177.4 & 0.0 & 3.3 & 66.5 & 245.8 & 628.0 \\
SM & 118.00 & 7.73 & 65.56 & 28.00 & 50.50 & 108.0 & 191.00 & 191.0 \\
NDVI & 0.16814 & 0.00556 & 0.0472 & 0.009 & 0.139 & 0.168 & 0.205 & 0.277 \\
IOD & 0.0643 & 0.0334 & 0.283 & -0.486 & -0.151 & 0.0413 & 0.3115 & 0.749 \\
SOI & -2.00 & 1.04 & 8.82 & -22.00 & -7.75 & -1.35 & 4.13 & 13.90 \\
NINA & 0.277 & 0.101 & 0.856 & -0.930 & -0.320 & 0.095 & 0.547 & 2.570 \\
Population Growth & 2.784 & 0.107 & 0.911 & 1.620 & 2.120 & 2.510 & 3.217 & 5.250 \\
\hline \multicolumn{1}{r}{ A. Training } & & & & Dinajpur & & & & \\
\hline Rainfall & 167.7 & 13.3 & 200.2 & 0.0 & 3.0 & 71.0 & 288.5 & 1026.0 \\
Tave & 25.523 & 0.881 & 13.31 & 13.2 & 21.50 & 26.70 & 28.60 & 213.20 \\
SM & 127.97 & 4.47 & 67.49 & 29.00 & 60.00 & 124.0 & 203.0 & 203.00 \\
NDVI & 0.217 & 0.005 & 0.0827 & 0.063 & 0.152 & 0.199 & 0.270 & 0.446 \\
IOD & -0.014 & 0.024 & 0.361 & -0.887 & -0.251 & -0.027 & 0.164 & 1.473 \\
SOI & -0.004 & 0.746 & 11.264 & -28.6 & -7.875 & 0.20 & 8.825 & 27.100 \\
NINA & -0.078 & 0.057 & 0.862 & -1.79 & -0.720 & -0.115 & 0.450 & 2.420 \\
Population Growth & 2.034 & 0.025 & 0.384 & 1.06 & 1.830 & 1.95 & 2.260 & 4.150 \\
\multicolumn{1}{c}{ B. Testing } & & & & & & & & \\
Rainfall & 143.9 & 20.2 & 171.5 & 0.0 & 1.3 & 68.0 & 256.5 & 640.0 \\
Tave & 28.785 & 0.587 & 4.981 & 14.5 & 25.70 & 29.75 & 32.375 & 37.300 \\
SM & 120.85 & 8.17 & 69.35 & 26.00 & 48.0 & 115.0 & 203.00 & 203.00 \\
NDVI & 0.218 & 0.009 & 0.082 & 0.068 & 0.149 & 0.205 & 0.2877 & 0.392 \\
IOD & 0.064 & 0.033 & 0.283 & -0.486 & -0.151 & 0.041 & 0.3115 & 0.749 \\
SOI & -2.00 & 1.04 & 8.82 & -22.0 & -7.75 & -1.35 & 4.13 & 13.90 \\
NINA & 0.277 & 0.101 & 0.856 & -0.930 & -0.32 & 0.095 & 0.547 & 2.570 \\
Population Growth & 2.784 & 0.107 & 0.911 & 1.620 & 2.12 & 2.510 & 3.218 & 5.250 \\
\hline
\end{tabular}

281

282

283

284

285

286

287

288

289

290

291

292

293

294

Note: SE Mean: Standard Error of mean, St Dev: Standard deviation, Q1: First Quartile, Median: Middle number, Q3: Third Quartile.

\subsection{Selection of best input combination using the sub-set regression and sensitivity analyses}

The present study evaluated eight input combinations for exploring the best combination for GWL prediction model. The combinations are: C1) SM; C2) SM, Population Growth; C3) Rainfall, SM, Population Growth; C4) Rainfall, SM, IOD, Population Growth; C5) Rainfall, SM, NDVI, IOD, Population Growth; C6) Rainfall, SM, IOD, SOI, Nina, Population Growth; C7)

Rainfall, Tave, SM, IOD, SOI, Nina, Population Growth; C8) Rainfall, Tave, SM, NDVI, IOD, SOI, Nina, Population Growth. The present study employed Mean Square Error (MSE), $R^{2}$, adjusted $R^{2}$, Mallow's CP, Akaike Information Criterion (AIC), Amemiya Prediction Criterion (PC), and Schwarz Bayesian Criterion (SBC) statistical tools for finding the best input combination for predicting GWL. Table 4 presents the results obtained using different methods. On average, the combination, $\mathrm{C} 1$, showed the lowest performance at all the wells. The input combination, $\mathrm{C} 8$, showed the best performance with higher values of $R^{2}$, adjusted $R^{2}$, 

Amemiya's PC and lower values of MSE, Mallows' Cp, AIC, SBC at all the wells (Table 4). The results indicate a significant influence of all input variables on GWL in the study. Therefore, all

297 the variables are required for reliable prediction of GWL in the study area.

298 Table 4: Statistical assessment of eight input combinations on model performance 299

\begin{tabular}{|c|c|c|c|c|c|c|c|}
\hline $\begin{array}{l}\text { Input } \\
\text { parameters }\end{array}$ & MSE & R square & $\begin{array}{l}\text { Adjusted } \\
\text { r square }\end{array}$ & $\begin{array}{l}\text { Mallows' } \\
\text { Cp }\end{array}$ & AIC & $\begin{array}{l}\text { Schwarz's } \\
\text { SBC }\end{array}$ & $\begin{array}{l}\text { Amemiya's } \\
\text { PC }\end{array}$ \\
\hline & & & Rangpur & & & & \\
\hline C1 & 0.61 & 0.22 & 0.217 & 9.996 & -147.534 & -139.052 & 0.783 \\
\hline $\mathrm{C} 2$ & 0.599 & 0.236 & 0.231 & 5.455 & -150.941 & -139.83 & 0.774 \\
\hline $\mathbf{C 3}$ & 0.595 & 0.243 & 0.236 & 4.785 & -151.629 & -136.814 & 0.772 \\
\hline $\mathrm{C4}$ & 0.593 & 0.249 & 0.239 & 9 & -151.923 & -133.404 & 0.771 \\
\hline C5 & 0.592 & 0.252 & 0.24 & 5.271 & -151.202 & -128.98 & 0.773 \\
\hline C6 & 0.594 & 0.257 & 0.238 & 5.306 & -151.219 & -125.292 & 0.773 \\
\hline C7 & 0.592 & 0.258 & 0.24 & 7.004 & -149.53 & -119.9 & 0.777 \\
\hline \multirow[t]{2}{*}{ C8 } & 0.59 & 0.258 & 0.242 & 4.524 & -146.46 & -114.2 & 0.785 \\
\hline & & & Rangpur & & & & \\
\hline C1 & 0.756 & 0.199 & 0.196 & 7.657 & -76.191 & -68.784 & 0.806 \\
\hline $\mathrm{C2}$ & 0.764 & 0.209 & 0.204 & 5.894 & -77.932 & -66.821 & 0.802 \\
\hline C3 & 0.76 & 0.215 & 0.207 & 5.533 & -78.304 & -63.488 & 0.8 \\
\hline $\mathrm{C} 4$ & 0.758 & 0.22 & 0.209 & 9 & -78.043 & -59.524 & 0.801 \\
\hline C5 & 0.757 & 0.224 & 0.211 & 6.163 & -77.721 & -55.498 & 0.802 \\
\hline C6 & 0.755 & 0.229 & 0.213 & 6.337 & -77.589 & -51.662 & 0.802 \\
\hline C7 & 0.754 & 0.232 & 0.214 & 7.186 & -76.772 & -47.142 & 0.805 \\
\hline \multirow[t]{2}{*}{ C8 } & 0.771 & 0.233 & 0.211 & 5.813 & -74.964 & -41.63 & 0.809 \\
\hline & & & Nilphama & & & & \\
\hline C1 & 0.312 & 0.127 & 0.124 & 8.409 & -346.994 & -339.586 & 0.879 \\
\hline $\mathrm{C} 2$ & 0.307 & 0.145 & 0.14 & 3.824 & -351.555 & -340.444 & 0.866 \\
\hline $\mathrm{C} 3$ & 0.306 & 0.162 & 0.142 & 9 & -355.443 & -340.627 & 0.855 \\
\hline C4 & 0.302 & 0.164 & 0.153 & 1.406 & -354.09 & -335.571 & 0.859 \\
\hline C5 & 0.303 & 0.164 & 0.15 & 3.192 & -352.311 & -330.088 & 0.864 \\
\hline C6 & 0.304 & 0.165 & 0.148 & 5.088 & -350.418 & -324.492 & 0.869 \\
\hline C7 & 0.305 & 0.165 & 0.145 & 7.037 & -348.471 & -318.841 & 0.875 \\
\hline \multirow[t]{2}{*}{ C8 } & 0.302 & 0.165 & 0.154 & 0.036 & -346.509 & -313.175 & 0.881 \\
\hline & & & Nilphama & & & & \\
\hline C1 & 0.861 & 0.309 & 0.307 & 78.415 & -104.506 & -71.172 & 0.601 \\
\hline $\mathrm{C} 2$ & 0.742 & 0.407 & 0.403 & 27.392 & -86.704 & -75.593 & 0.578 \\
\hline $\mathrm{C3}$ & 0.711 & 0.434 & 0.428 & 14.919 & -98.527 & -83.712 & 0.563 \\
\hline C4 & 0.685 & 0.451 & 0.444 & 7.219 & -106.162 & -87.643 & 0.559 \\
\hline
\end{tabular}




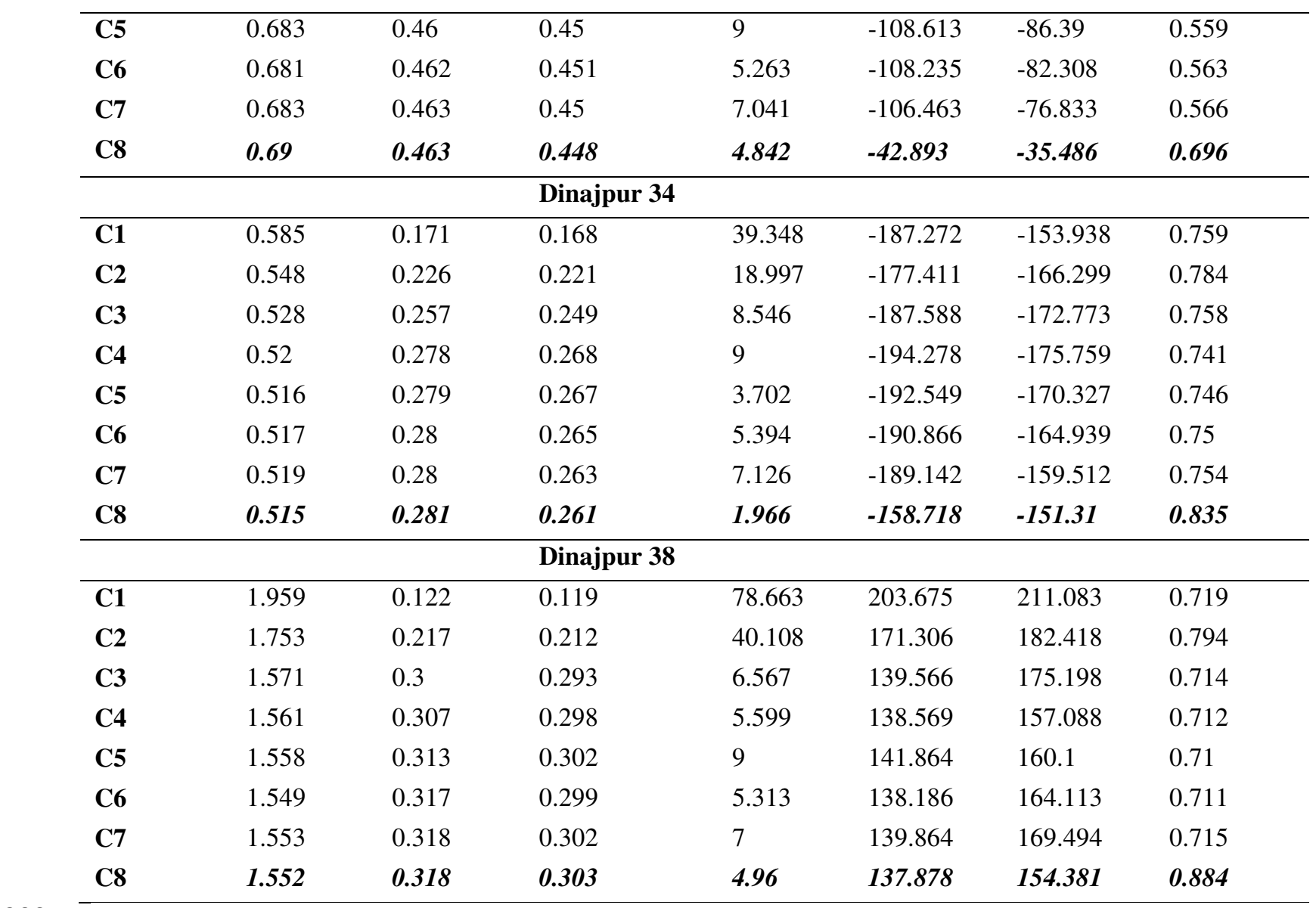

\subsection{Comparison of nine data-driven models in groundwater level prediction}

Figure 6 represents the scatter plot of monthly observed and predicted GWL (m) estimated using nine ML models (both standalone and hybrid) at the six selected wells in the study area in the 304 training stage. The predicted GWL (m) by the hybrid model LWLR- GPR-PUK showed the highest alignment with the diagonal line of the scatter plot, indicating the best performance of the 306 model in replicating observed GWL (m). Among the six wells, Dinajpur-34 showed the least 307 scattered points in the scatter plot for all the predicted models. The Nilphamari-44 and Dinajpur30838 wells showed the most scattered points for all the predicted models.

309 Figure 7 depicts the scatter plots for the testing stage. Like the scatter plot of the training stage, 310 the predicted GWL (m) for the hybrid model LWLR-GPR-PUK showed the closest position to 
311 the observed GWL (m) at the testing stage (Figure 7). The predicted GWL at Dinajpur-34 well 312 showed the least scattered points along the diagonal line. 

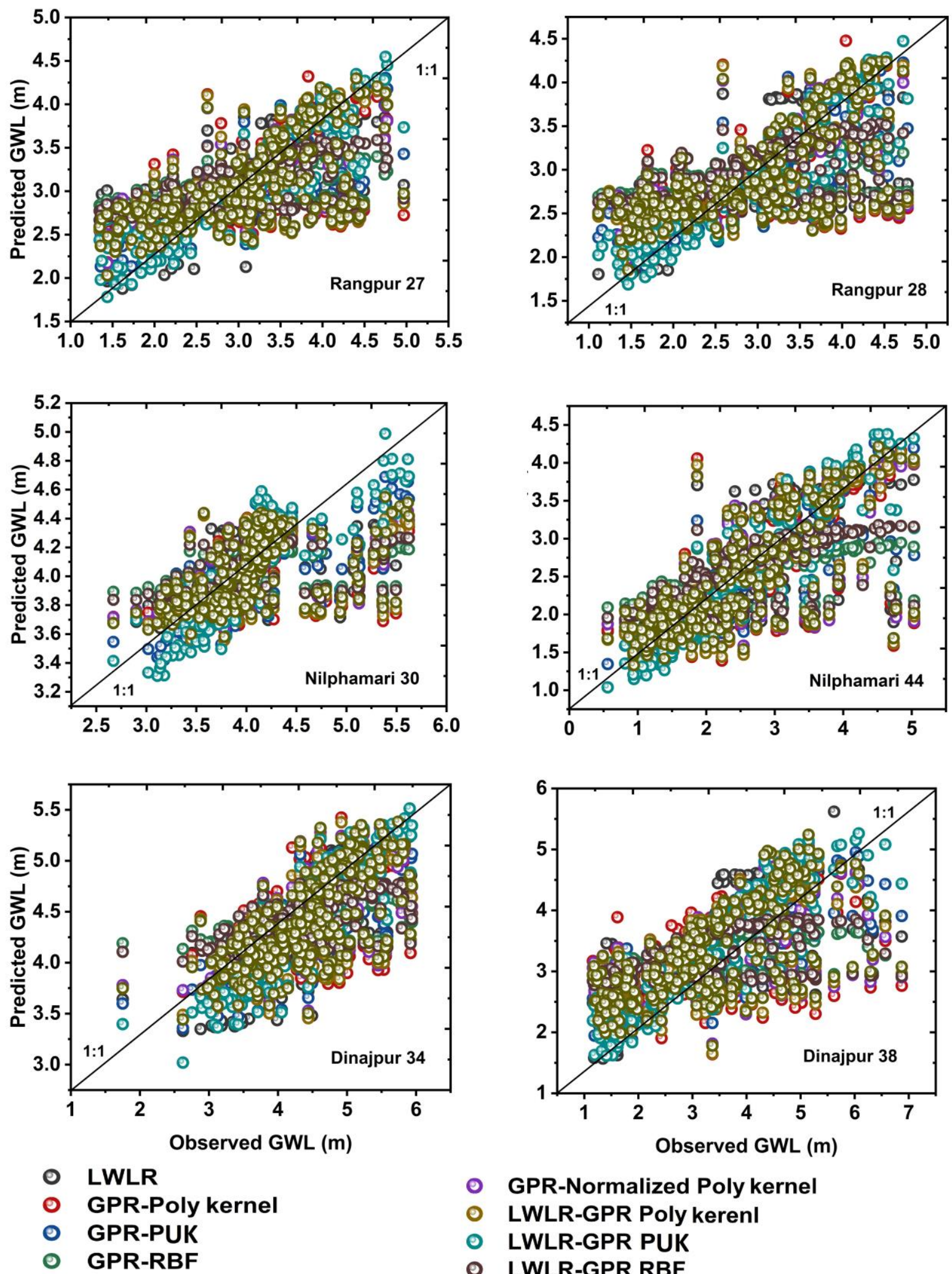

- GPR-Normalized Poly kernel

○ LWLR-GPR Poly kerenl

O LWLR-GPR PUK

O LWLR-GPR RBF

○ LWLR-GPR Normalized poly kerenl

315 Figure 6: Scatter plots of predicted GWL (m) using nine machine learning models against the 

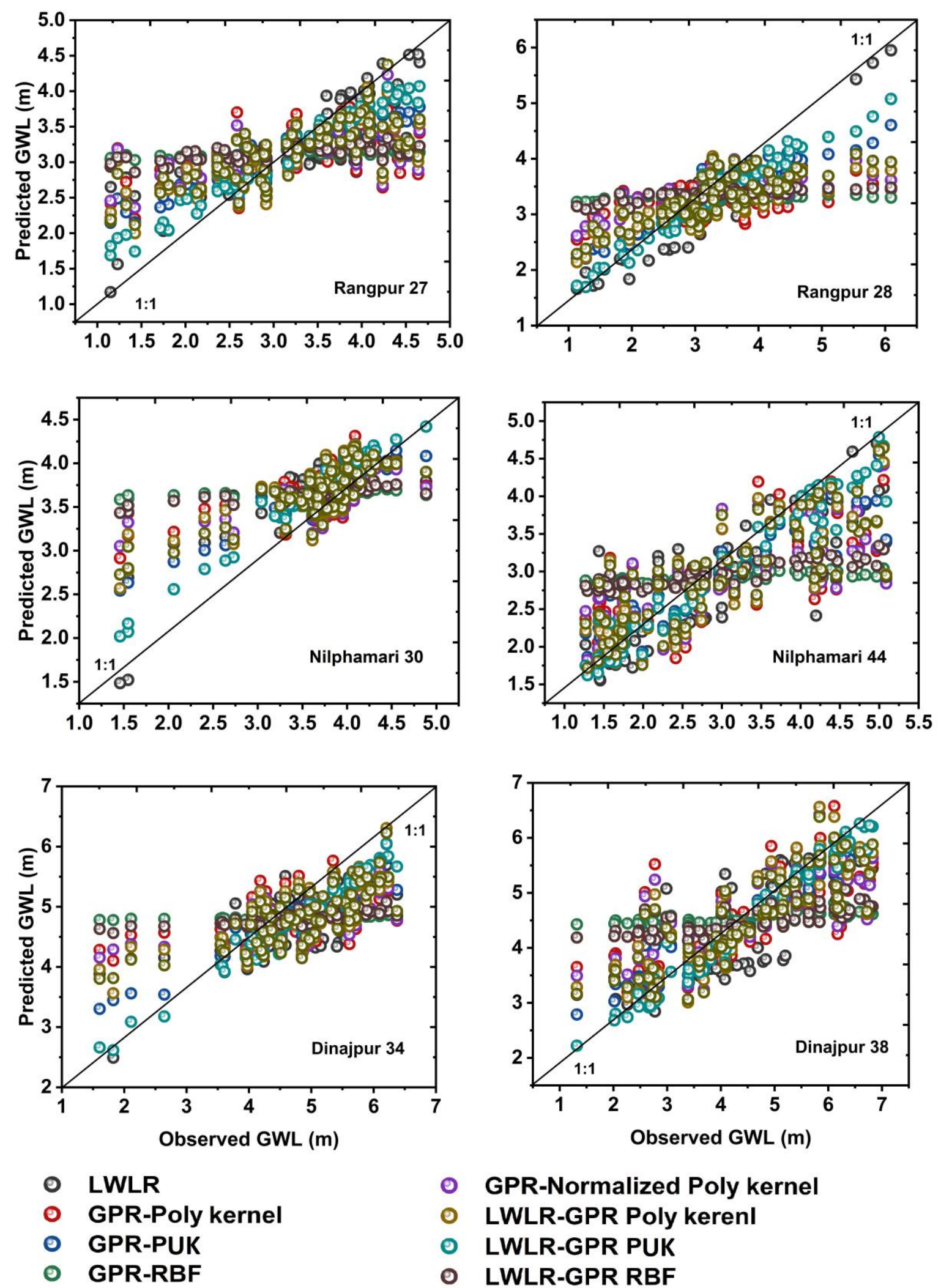

- GPR-Normalized Poly kernel

- LWLR-GPR Poly kerenl

- LWLR-GPR PUK

○ GPR-RBF

- LWLR-GPR RBF

- LWLR-GPR Normalized Poly kerenl

Figure 7: Scatter plots of predicted GWL (m) using nine machine learning models against the 
corresponding observed GWL (m) at six selected wells in the testing stage

322 Figure 8 shows the long-term mean monthly time series plot of both observed and predicted 323 GWL (m) during training and testing stages. GWL showed an abrupt increase in the year 2014 at 324 all wells during model testing. Overall, the GWL showed the highest fluctuation (generally 3-4.5 $325 \mathrm{~m})$ at Nilphamari-30 and the lowest fluctuating, from 1-5 m, at Rangpur-27, Rangpur-28, and 326 Nilphamari-44 wells. Besides, GWL showed very high fluctuation $(1-6.5 \mathrm{~m})$ at the rest of the 327 two wells. All the models could replicate the observed GWL at all the stations with reasonable 328 accuracy during training and testing periods. However, there were few exceptions. All the ML 329 models underestimated observed GWL during 1999-2002 at Nilphamari-30 (Figure 8). Overall, 330 the least performance in reconstructing the GWL time series was by GPR-RBF during both the 331 training and testing stage at all wells. On the other hand, LWLR- GPR-PUK showed the highest 332 performance in replicating GWL time series, followed by GPR-PUK, LWLR, LWLR- GPR333 NPK, LWLR- GPR-Poly Kernel, GPR-NPK, GPR-Poly Kernel and LWLR- GPR-RBF.

334 Figures 9 and 10 show the Violin plots displaying the error GWL data distribution estimated by 335 nine models at six different wells during the training and testing stage. Like the previous 336 statistical results, violin plots also indicated the LWLR- GPR-PUK as the best model, with fewer 337 errors than the other models at all the wells during both training and testing stages. The error 338 values were fewer at the testing stage compared to the training stage. 
343 

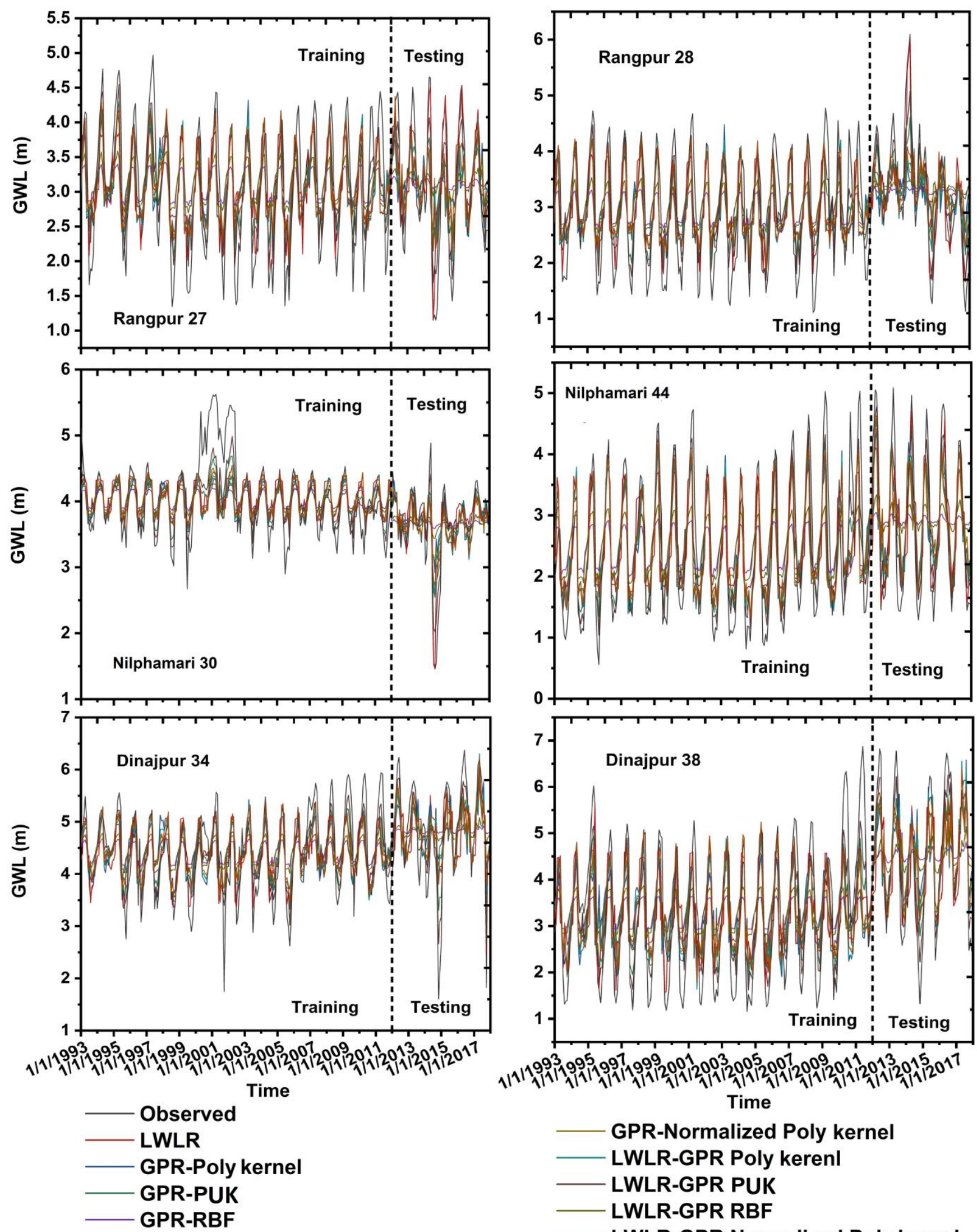

Time

GPR-Normalized Poly kernel - LWLR-GPR Poly kerenl LWLR-GPR PUK LWLR-GPR RBF LWLR-GPR Normalized Poly kerenI 
Figure 8: The time series plot of GWL (m) for both the observed and predicted values during the training and testing stage at six selected wells of the northern part of North-western Bangladesh
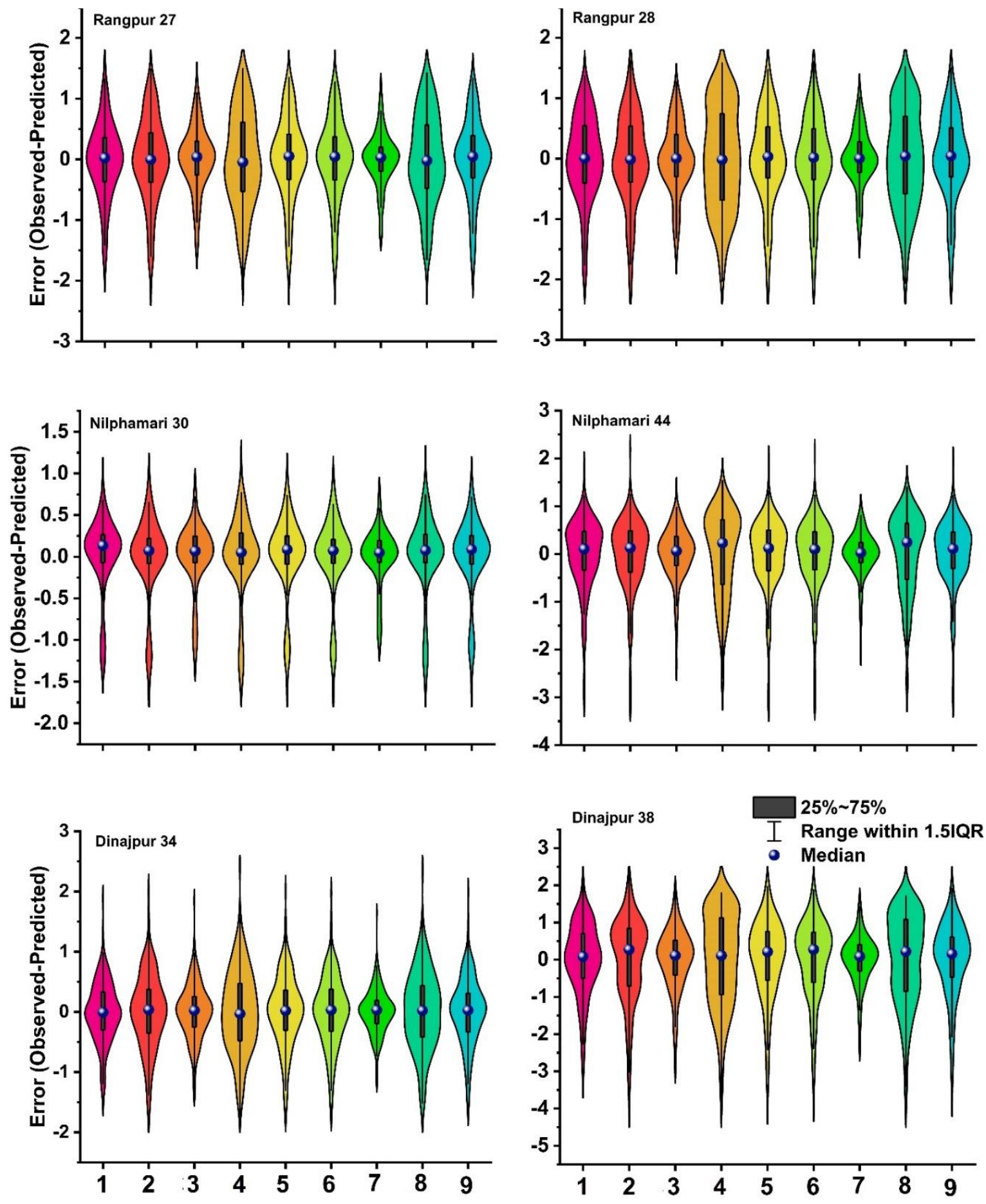

Figure 9: Violin plot displaying an error (observed-predicted) for nine models (1. LWLR, 2.

349 GPR poly kernel, 3. GPR-PUK,4. GPR-RBF, 5. GPR-NPK, 6. LWLR- GPR-poly kernel, 7. 

the training stage
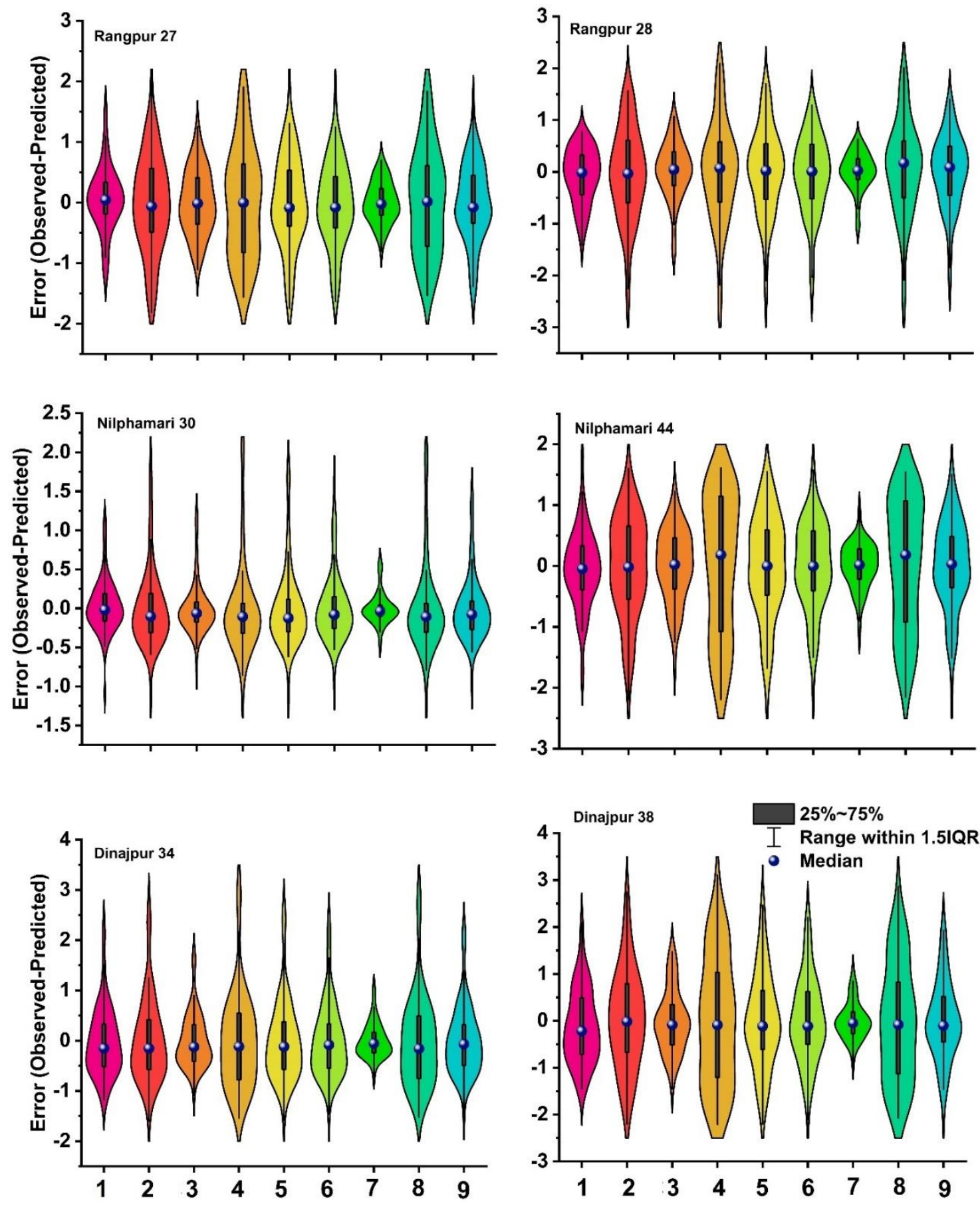

Figure 10: Violin plot displaying an error (observed-predicted) for nine models (1. LWLR, 2.

354 GPR-poly kernel, 3. GPR-PUK, 4. GPR-RBF, 5. GPR-NPK, 6. LWLR- GPR-poly kernel, 7. 
LWLR- GPR-PUK, 8. LWLR- GPR- RBF, 9. LWLR- GPR-NPK) at six different wells during

356 the testing stage

357 3.4 Statistical evaluation model performance

358 Table 5 shows the performance of the models in predicting monthly GWL during both the

359 training and testing stage at six selected wells based RMSE, MAE, RAE, RRSE and CC. All 360 models showed an RMSE below 1, except at Dinajpur-38 during both the training and testing 361 stage. All the models showed the least error at Nilphamari-30 during both the training and testing 362 stage. Overall, the results obtained using statistical metrics were very similar to those obtained 363 using scatter plots and time series plots (Figures 5,6 and 7). The results established the best 364 performance of LWLR- GPR-PUK model. The RMSE of LWLR- GPR-PUK model ranges from 3650.36 to 0.65 , MAE from 0.23 to 0.47 , RAE between 24.67 and $36.35 \%$ and RRSE between 27.79 366 and $36.78 \%$ during training. In the testing period, the RMSE were between 20 and 39, MAE 367 from 0.14 to 0.30 , RAE between 34.98 and $58.38 \%$ and RRSE between 42.13 and $61.35 \%$. The 368 highest CC (0.97-0.98 at the testing stage and 0.82-0.92 at training stage) was obtained for GPR369 PUK Kernel, followed by LWLR, LWLR- GPR- NPK, LWLR-GPR-Poly Kernel, GPR-NPK, 370 GPR-Poly Kernel, LWLR-GPR-RBF and GPR-RBF.

371 The results presented above indicate hybrid model LWLR-GPR-PUK as the best performed and 372 GPR-RBF as the least performed model in predicting local level GWL fluctuation in the study 373 area. Therefore, the LWLR-GPR-PUK model can be suggested for reliable prediction of local 374 level GWL fluctuation in the study area.

375 
377 Table 5: Statistical performance of the selected models during training and testing stage at six

378 selected wells

\begin{tabular}{|c|c|c|c|c|c|c|c|c|c|c|}
\hline \multirow{2}{*}{ Models } & \multicolumn{5}{|c|}{ Training period } & \multicolumn{5}{|c|}{ Testing period } \\
\hline & RMSE & MAE & RAE (\%) & RRSE (\%) & $\mathrm{CC}$ & RMSE & MAE & RAE (\%) & RRSE (\%) & $\mathrm{CC}$ \\
\hline & \multicolumn{10}{|c|}{ Rangpur 27} \\
\hline 1 & 0.62 & 0.47 & 65.12 & 71.96 & 0.70 & 0.52 & 0.38 & 48.80 & 56.33 & 0.84 \\
\hline 2 & 0.69 & 0.53 & 74.56 & 80.92 & 0.59 & 0.79 & 0.64 & 81.05 & 85.34 & 0.54 \\
\hline 3 & 0.52 & 0.39 & 54.33 & 60.54 & 0.82 & 0.52 & 0.43 & 54.74 & 56.57 & 0.94 \\
\hline 4 & 0.77 & 0.63 & 88.41 & 89.56 & 0.53 & 0.91 & 0.76 & 97.04 & 97.86 & 0.42 \\
\hline 5 & 0.68 & 0.51 & 72.05 & 79.18 & 0.61 & 0.75 & 0.60 & 76.25 & 80.69 & 0.64 \\
\hline 6 & 0.67 & 0.50 & 69.97 & 77.28 & 0.64 & 0.68 & 0.54 & 69.07 & 73.56 & 0.73 \\
\hline 7 & 0.43 & 0.31 & 43.21 & 49.89 & 0.89 & 0.33 & 0.27 & 34.92 & 36.11 & 0.97 \\
\hline 8 & 0.74 & 0.60 & 83.67 & 85.70 & 0.57 & 0.86 & 0.72 & 91.79 & 93.22 & 0.62 \\
\hline \multirow[t]{2}{*}{9} & 0.65 & 0.49 & 67.96 & 75.68 & 0.66 & 0.64 & 0.51 & 64.67 & 68.70 & 0.79 \\
\hline & \multicolumn{10}{|c|}{ Rangpur 28} \\
\hline 1 & 0.69 & 0.54 & 65.69 & 72.68 & 0.69 & 0.52 & 0.42 & 56.85 & 53.09 & 0.86 \\
\hline 2 & 0.74 & 0.58 & 70.11 & 78.27 & 0.62 & 0.90 & 0.70 & 93.76 & 90.67 & 0.45 \\
\hline 3 & 0.56 & 0.43 & 52.14 & 59.39 & 0.83 & 0.54 & 0.40 & 54.36 & 54.33 & 0.94 \\
\hline 4 & 0.85 & 0.72 & 86.97 & 88.87 & 0.55 & 0.98 & 0.74 & 98.93 & 98.78 & 0.43 \\
\hline 5 & 0.74 & 0.57 & 69.16 & 77.49 & 0.63 & 0.83 & 0.64 & 84.92 & 84.03 & 0.63 \\
\hline 6 & 0.72 & 0.55 & 66.37 & 75.45 & 0.66 & 0.74 & 0.58 & 77.14 & 75.43 & 0.76 \\
\hline 7 & 0.47 & 0.34 & 41.77 & 49.16 & 0.89 & 0.36 & 0.27 & 36.35 & 36.78 & 0.97 \\
\hline 8 & 0.81 & 0.68 & 81.82 & 84.81 & 0.59 & 0.93 & 0.71 & 94.88 & 93.48 & 0.73 \\
\hline \multirow[t]{2}{*}{9} & 0.71 & 0.54 & 65.42 & 74.41 & 0.67 & 0.69 & 0.54 & 71.85 & 70.18 & 0.81 \\
\hline & \multicolumn{10}{|c|}{ Nilphamari 30} \\
\hline 1 & 0.45 & 0.32 & 80.64 & 82.42 & 0.57 & 0.33 & 0.23 & 58.13 & 53.53 & 0.86 \\
\hline 2 & 0.50 & 0.33 & 83.31 & 90.98 & 0.41 & 0.51 & 0.36 & 88.86 & 81.31 & 0.60 \\
\hline 3 & 0.39 & 0.28 & 69.43 & 72.03 & 0.72 & 0.33 & 0.22 & 54.67 & 53.64 & 0.94 \\
\hline 4 & 0.51 & 0.34 & 85.67 & 92.16 & 0.46 & 0.61 & 0.39 & 97.30 & 97.66 & 0.51 \\
\hline 5 & 0.49 & 0.33 & 83.77 & 88.87 & 0.46 & 0.49 & 0.34 & 85.03 & 78.89 & 0.66 \\
\hline 6 & 0.49 & 0.32 & 81.10 & 88.17 & 0.47 & 0.44 & 0.31 & 76.56 & 69.82 & 0.76 \\
\hline 7 & 0.34 & 0.23 & 58.38 & 61.35 & 0.82 & 0.20 & 0.14 & 34.28 & 32.30 & 0.98 \\
\hline 8 & 0.49 & 0.33 & 83.19 & 89.62 & 0.48 & 0.58 & 0.38 & 92.50 & 92.03 & 0.71 \\
\hline \multirow[t]{2}{*}{9} & 0.47 & 0.32 & 81.64 & 85.86 & 0.52 & 0.41 & 0.29 & 72.75 & 66.59 & 0.81 \\
\hline & \multicolumn{10}{|c|}{ Nilphamari 44} \\
\hline 1 & 0.72 & 0.54 & 59.80 & 67.28 & 0.74 & 0.62 & 0.46 & 45.15 & 52.55 & 0.86 \\
\hline 2 & 0.73 & 0.54 & 59.97 & 68.61 & 0.73 & 0.82 & 0.67 & 65.37 & 69.95 & 0.74 \\
\hline 3 & 0.55 & 0.40 & 44.49 & 51.69 & 0.87 & 0.58 & 0.47 & 45.76 & 49.93 & 0.93 \\
\hline 4 & 0.89 & 0.74 & 82.13 & 83.48 & 0.67 & 1.14 & 0.99 & 96.58 & 96.83 & 0.70 \\
\hline 5 & 0.72 & 0.53 & 59.23 & 67.86 & 0.73 & 0.82 & 0.67 & 65.35 & 70.31 & 0.74 \\
\hline 6 & 0.70 & 0.51 & 57.34 & 66.28 & 0.75 & 0.72 & 0.57 & 55.55 & 60.99 & 0.82 \\
\hline 7 & 0.44 & 0.31 & 34.98 & 42.13 & 0.92 & 0.37 & 0.29 & 28.14 & 31.47 & 0.97 \\
\hline 8 & 0.83 & 0.68 & 75.17 & 77.75 & 0.70 & 1.06 & 0.92 & 89.40 & 89.80 & 0.80 \\
\hline \multirow[t]{2}{*}{9} & 0.69 & 0.50 & 55.69 & 64.82 & 0.76 & 0.72 & 0.57 & 55.52 & 61.06 & 0.82 \\
\hline & \multicolumn{10}{|c|}{ Dinajpur 34} \\
\hline 1 & 0.49 & 0.37 & 61.54 & 65.72 & 0.76 & 0.67 & 0.52 & 70.30 & 68.72 & 0.74 \\
\hline 2 & 0.61 & 0.47 & 77.25 & 80.53 & 0.59 & 0.83 & 0.64 & 85.46 & 85.04 & 0.54 \\
\hline 3 & 0.44 & 0.33 & 55.00 & 58.69 & 0.83 & 0.53 & 0.41 & 55.92 & 54.17 & 0.93 \\
\hline 4 & 0.67 & 0.54 & 88.82 & 89.23 & 0.55 & 0.96 & 0.74 & 98.68 & 98.25 & 0.51 \\
\hline 5 & 0.58 & 0.44 & 72.08 & 76.69 & 0.64 & 0.79 & 0.60 & 80.19 & 80.79 & 0.63 \\
\hline
\end{tabular}




\begin{tabular}{l|lllll|lllll}
\hline 6 & 0.56 & 0.43 & 71.21 & 75.06 & 0.66 & 0.73 & 0.56 & 74.68 & 74.03 & 0.71 \\
$\mathbf{7}$ & $\mathbf{0 . 3 6}$ & $\mathbf{0 . 2 6}$ & $\mathbf{4 3 . 7 0}$ & $\mathbf{4 7 . 4 0}$ & $\mathbf{0 . 9 0}$ & $\mathbf{0 . 3 3}$ & $\mathbf{0 . 2 6}$ & $\mathbf{3 5 . 0 3}$ & $\mathbf{3 4 . 2 2}$ & $\mathbf{0 . 9 8}$ \\
8 & 0.64 & 0.52 & 84.68 & 85.29 & 0.59 & 0.91 & 0.70 & 94.15 & 93.08 & 0.70 \\
9 & 0.54 & 0.41 & 67.36 & 72.12 & 0.70 & 0.68 & 0.52 & 69.05 & 69.63 & 0.77 \\
\hline & \multicolumn{8}{|c}{ Dinajpur 38 } \\
\cline { 2 - 10 } 1 & 0.96 & 0.74 & 64.47 & 69.98 & 0.73 & 0.80 & 0.66 & 54.37 & 56.34 & 0.84 \\
2 & 1.13 & 0.90 & 78.57 & 82.15 & 0.57 & 1.07 & 0.85 & 70.27 & 75.08 & 0.68 \\
3 & 0.81 & 0.61 & 53.52 & 59.15 & 0.83 & 0.66 & 0.52 & 42.65 & 46.85 & 0.95 \\
4 & 1.26 & 1.05 & 91.81 & 91.68 & 0.50 & 1.36 & 1.16 & 95.42 & 96.11 & 0.58 \\
5 & 1.07 & 0.82 & 71.58 & 77.73 & 0.63 & 1.00 & 0.78 & 64.63 & 70.78 & 0.74 \\
6 & 1.04 & 0.81 & 70.61 & 75.86 & 0.66 & 0.89 & 0.70 & 57.98 & 63.18 & 0.80 \\
$\mathbf{7}$ & $\mathbf{0 . 6 5}$ & $\mathbf{0 . 4 7}$ & $\mathbf{4 1 . 6 9}$ & $\mathbf{4 7 . 2 9}$ & $\mathbf{0 . 9 0}$ & $\mathbf{0 . 3 9}$ & $\mathbf{0 . 3 0}$ & $\mathbf{2 4 . 6 7}$ & $\mathbf{2 7 . 7 9}$ & $\mathbf{0 . 9 8}$ \\
8 & 1.20 & 1.01 & 87.94 & 87.89 & 0.55 & 1.25 & 1.05 & 86.60 & 88.46 & 0.72 \\
9 & 1.00 & 0.75 & 65.68 & 72.84 & 0.69 & 0.83 & 0.64 & 52.77 & 58.98 & 0.85 \\
\hline
\end{tabular}

Note: Models: (1) LWLR, (2) GPs-poly kernel, (3) GPs-PUK, (4) GPs-RBF, (5) GPs-Normalized poly kernel,

380 (6) LWLR- GPs-poly kernel, (7) LWLR- GPs-PUK, (8) LWLR- GPs- RBF, (9) LWLR- GPs- Normalized poly kernel

\section{Discussion}

383 Though advanced models and soft computing tools have been extensively utilized in GWL

384 prediction studies, the hydrogeological processes should not be ignored. In the present study, the

385 findings of this study imply that the LWLR-GPR-PUK is a robust algorithm for the prediction of

386 GWL at local scale in a humid climatic region like Bangladesh. The models developed in this

387 study should be compared with other soft computing models, i.e., ANN, ANFIS, ELM and RF

388 and their ensemble with metaheuristic models to evaluate the models' relative performance.

389 Furthermore, the proposed modeling algorithms can be also for predicting groundwater

390 contamination, groundwater vulnerability and managed aquifer recharge (Islam et al. 2020).

391 In recent times, the drought-prone humid region of northern Bangladesh has experienced severe

392 scarcity of GW due to the declination of GWL. The present research revealed that the declination

393

of GWL is much greater in the wells of Rangpur than that of Dinajpur and Nilphamari. The main

reason is that the flow of the Teesta River occurs at the upper part of the Rangpur district, and

395 the base flow happens in the SW direction because of the normal slope, triggering the minimum 
397 is dominated by silty clay soil, which belongs to relatively lower hydraulic conductivity 398 characteristics (Zinat et al. 2020). Consequently, groundwater recharge from rainfall is very low. 399 On the other hand, the possibilities of groundwater recharge from river and precipitation are 400 comparatively higher in Dinajpur district, as the flow of Atrai River.

401 The decreasing trend of precipitation, consistent with a widespread and prevailing decreasing 402 trend in GWL over the North-western region, cannot be ignored as a responsible factor. Local 403 geology characterizes shallow aquifers in Bangladesh and largely controls the timing and 404 pathways of groundwater recharge to aquifers (WARPO 2000). The declining shallow 405 groundwater storage in North-western Bangladesh relates to the intensity of abstraction and areas 406 of the high thickness of surface clay where rainfall-fed recharge rates are low due to the low 407 hydraulic conductivity of this subsurface geology (Shamsudduha et al. 2011). Hence, earlier 408 evidence indicates that rigorous abstraction of groundwater for irrigation, decreasing 409 precipitation that is one of the impacts of climate change and local geology of the study region, 410 can be attributed to rapidly declining GWL in the drought-prone urban area.

411 In this region, the rainfall has reduced $10-45 \mathrm{~mm} /$ year over the past 12 years, leading to 412 decreased natural recharge (Jahan et al. 2010). The abuse of existing GWL, mostly being 413 extracted for paddy farming, rice mill operations, domestic and other industrial purposes, is an 414 alarming issue where groundwater provides $80 \%$ of the water needed for rice irrigation. Here, 415 random use of water in industry and agriculture is causing GWL declination. On average, GWL 416 varies between 1 and $6 \mathrm{~m}$ in the northern region, which is consistent with the Master Plan 417 Organization (MPO 1987) claim, which stated that groundwater is mainly available within $5 \mathrm{~m}$ 418 of ground within alluvial aquifers. Evidence suggests that due to low rainfall in the short 419 monsoon season and less available soil moisture, aquifer replenishment slowly ends during the 
420 dry season (Jahan et al., 2010). In the last ten years, the rate of GWL in Rangpur, Niphamari and

421 Dinajpur urban regions has dropped by $0.05 \mathrm{~m}, 0.03 \mathrm{~m}$, and $0.01 \mathrm{~m}$, respectively, which is also

422 consistent with the result of Dey et al. (2017). Besides, silty loam, the predominant soil type, has

423 a medium permeability, which may be partly responsible for replenishing the depleted GWLs.

424 On the other hand, loamy soil, the dominant soil type in the Dinajpur district, has an elevated

425 permeability level. Therefore, the potential of groundwater recharge from rainfall and surface

426 water sources is a lesser amount here and decrease in the wetland region resulting in a significant

427 declination of GWL in the Rangpur district.

428 River water use, aquifers' safe yields management, natural and artificial aquifers recharging,

429 rainwater harvesting, and wastewater use are the likely choices for reducing pressure on

430 groundwater and prevent declination of GWL. Also, practices such as mulching can increase the

431 water-holding capacity of field soils and decrease evaporation. Organic mulching, by increasing

432 soil organic matter, can also aid groundwater recharge. Population growth, rapid urbanization,

433 climate change, and poor water management policy have threatened groundwater resources in

434 the study area (Salam et al. 2020a). Thus, strategies such as artificial recharge of aquifers,

435 rainwater harvesting, water-saving technologies and integrated water resources management

436 need to be implemented.

437 Some of the vital indicators of GWL fluctuations, including bore-well depths closeness of well 438 from sink or source and hydrogeological features, e.g., aquifer porosity and permeability, are 439 ignored in this study due to unavailability data. Further investigation is essential by incorporating 440 these important hydrogeological parameters in data-driven tools to enhance short and mid-term 441 prediction accuracy and confirm these hybrid methods agree well with the theoretical and 442 numerical-based methods. 


\section{Conclusion}

444 The GWL in the study area has gradually declined over the last two decades because of rapid

445 urbanization and over-exploitation to meet the demand of the growing urban population. The

446 results showed all the factors considered in this study are important for the reliable estimation of

447 GWL at local scale. This indicates that complex interactions of various atmospheric variables

448 and land features determine GWL fluctuation in the local areas of North-western region. The

449 performance assessment of the nine data-driven models developed in this study suggests LWLR-

450 GPR-PUK as the best model for GWL estimation. The estimated average GWL fluctuation

451 varied from 0.4 to $1.25 \mathrm{~m}$. The outcomes obtained from the present work would help detect the

452 reasons for GWL declination at local level situated in urban regions under different hydro-

453 climatic settings. The proposed model would be useful, especially in the drought-prone areas

454 where the physical flow-based model implementation is difficult due to the lack of data. This

455 research would create new knowledge for sustainable groundwater management and aquifer 456 protection in the study areas for safeguarding the groundwater resources.

\section{Acknowledgements}

458 The authors acknowledge the Department of Disaster Management for all sorts of support for 459 this research project. We would like to acknowledge the Bangladesh Water Development Board 460 (BWDB) for providing groundwater level data for this research. The authors extend their 461 appreciation to the Deanship of Scientific Research at King Khalid University for funding this 462 work through Research Group under grant number (R.G.P.2 /194/42).

\section{Ethical approval}

464 Not applicable

465 Consent to Participate 
468 Not applicable

Data available

470 Data are available upon request on the corresponding author

471 Code availability

472 Not applicable

473 Author contributions

474 A.R.M.T.I., A.E., and R.S.., designed, planned, conceptualized, drafted the original manuscript, and R.S, M.

475 S.I was involved in statistical analysis, interpretation; S.C.P, J.M., and A.E., contributed instrumental setup,

476 data analysis, validation; B.Z.., and R.S., contributed to editing the manuscript, literature review, proofreading;

477 S.S., R.S., J.M., and A.R.M. T.I., were involved in software, mapping, and proofreading during the manuscript

478 drafting stage.

479 Conflict of interest

480 There is no conflict of interest to publish this work

481

482

483

484

485

486

487

488

489

490

491

492

493

494

\section{References}

1. Ahmadianfar, I., Jamei, M., Chu, X., 2020. A novel Hybrid Wavelet-Locally Weighted Linear Regression (W-LWLR) Model for Electrical Conductivity (EC) Prediction in Surface Water, Journal of Contaminant Hydrology, 232, 103641.

2. Akbari, M., Salmasi, F., Arvanaghi, H., Karbasi, M., \& Farsadizadeh, D. 2019. Application of Gaussian process regression model to predict discharge coefficient of Gated Piano Key Weir. Water Resources Management, 33(11), 3929-3947.

3. Alizamir, M., Kisi, O., Zounemat-Kermani, M., 2018. Modelling long-term groundwater fluctuations by extreme learning machine using hydro-climatic data. Hydrol. Sci. J. 63 (1), $63-73$.

4. Cleveland, W.S., Devlin, S.J., 1988. Locally weighted regression - an approach to regression-analysis by local fitting, J. Am. Stat. Assoc. 83 (403), 596-610.

5. Das, S (2021) Extreme rainfall estimation at ungauged locations: Information that needs to be included in low-lying monsoon climate regions like Bangladesh. J. Hydrol. 601, 126616. 
6. Das S, Islam ARMT (2021) Assessment of mapping of annual average rainfall in a tropical country like Bangladesh: remotely sensed output vs. kriging estimate, Theoretical and Applied climatology, DOI: 10.1007/s00704-021-03729-3

7. Dey, N. C., Saha, R., Parvez, M., Bala, S. K., Islam, A. K. M. S., Paul, J. K., et al. 2017. Sustainability of groundwater use for irrigation of dry-season crops in northwest Bangladesh. Groundwater for Sustainable Development, 4, 66-77.

8. Ghose B, Islam ARMT, Kamruzzaman M, Moniruzzaman M, Hu Z (2021) Climate-induced rice yield anomalies linked to large-scale atmospheric circulation in Bangladesh using multistatistical modeling, Theoretical and Applied climatology.

9. Gong, Y., Wang, Z., Xu, G., \& Zhang, Z. (2018). A comparative study of groundwater level forecasting using data-driven models based on ensemble empirical mode decomposition. Water, 10, 730.

10. Hasanuzzaman, M., Song, X., Han, D., Zhang, Y., Hussain, S. (2017) Prediction of Groundwater Dynamics for Sustainable Water Resource Management in Bogra District, Northwest Bangladesh, Water 2017, 9, 238; doi:10.3390/w9040238.

11. Huang, Z. Y., Lin, S., Long, L. L., Cao, J. Y., Luo, F., Qin, W. C., ... \& Gregersen, H. (2020). Predicting the morbidity of chronic obstructive pulmonary disease based on multiple locally weighted linear regression model with K-means clustering. International journal of medical informatics, 139, 104141.

12. Hosono, T., Yamada, C., Shibata, T., Tawara, Y., Wang, C.-Y., Manga, M., Rahman, A.T.M.S., Shimada, J., 2019. Coseismic groundwater drawdown along crustal ruptures during the $2016 \mathrm{Mw} 7.0$ Kumamoto earthquake. Water Resour. Res. 55 (7), 5891-5903.

13. Islam A.R.M.T., Mehra, B., Salam, R., Siddik, N.A., Patwary, M.A. (2021a). Insight into farmers' agricultural adaptive strategy to climate change in northern Bangladesh. Environment, Development, Sustainability, 23, 2439-2464.

14. Islam ARMT, Mamun AA, Rahman MM, Zahid A (2020) Simultaneous comparison of modified-integrated water quality and entropy weighted indices: Implication for safe drinking water in the coastal region of Bangladesh, Ecological Indicators, 113: 106229.

15. Islam ARMT, Talukdar S, Mahato S et al. (2021b). Flood susceptibility modelling using advanced ensemble machine learning models. Geoscience Frontiers, 12, 101075. 
16. Jahan, C. S., Islam, M. A., Mazumder, Q. H., Assaduzzaman, M., Islam, M. M., Islam, M. O., et al. (2007). Evaluation of depositional environment and aquifer condition in Barind area, Bangladesh using Gamma Ray Well Log Data. Journal Geological Society of India, 70, 1070-1076

17. Jahan, C.S., Mazumder, Q.H., Islam, A.T.M.M. and Adham, M.I. (2010). Impact of irrigation in Barind area, NW Bangladesh - an evaluation based on the meteorological parameters and fluctuation trend in groundwater table. Journal of the Geological Society of India, 76(2), pp.134-142.

18. Jamei, M., Ahmadianfar, I., 2019. Prediction of scour depth at piers with debris accumulation effects using linear genetic programming. Mar. Georesour. Geotechnol. 1-12.

19. Jamei, M., Ahmadianfar, I., Chu, X., \& Yaseen, Z. M. (2020). Estimation of triangular side orifice discharge coefficient under a free flow condition using data-driven models. Flow Measurement and Instrumentation, 77, 101878.

20. Kisi, O. (2015). Pan evaporation modeling using least square support vector machine, multivariate adaptive regression splines and M5 model tree. Journal of Hydrology, 528, pp. 312-320.

21. Koch, J., Berger, H., Henriksen, H.J., Sonnenborg, T.O. (2019). Modelling of the shallow water table at high spatial resolution using random forests. Hydrology and Earth System Sciences, 23(11), pp. 4603-4619.

22. Kumar, D., Roshni, T., Singh, A., Jha, M.K., Samu, P., (2020) Predicting groundwater depth fluctuations using deep learning, extreme learning machine and Gaussian process: a comparative study, Earth Science Informatics.

23. Kumar, M., Tiwari, N. K., \& Ranjan, S. (2019). Kernel function-based regression approaches for estimating the oxygen transfer performance of plunging hollow jet aerator. Journal of Achievements in Materials and Manufacturing Engineering, 95(2).

24. Kuss, A. J. M., and J. J. Gurdak (2014), Groundwater level response in U.S. principal aquifers to ENSO, NAO, PDO, and AMO, J. Hydrol., 519, 1939-1952.

25. Lal, A., Datta, B., (2020) Performance Evaluation of Homogeneous and Heterogeneous Ensemble Models for Groundwater Salinity Predictions: a Regional-Scale Comparison Study, Water Air Soil Pollut, 231:320. 
26. Mallick, J, Naiko MW, Talakdar S, Ahmed IA, Rahman A, Islam ARMT et al. (2021a) Developing groundwater potentiality models by coupling ensemble machine learning algorithms and statistical techniques for sustainable groundwater management, Geocarto International, DOI: $10.1080 / 10106049.2021 .1987535$

27. Mallick J, Talukder S, Islam ARMT, et al. (2021b) Proposing receiver operating characteristic-based sensitivity analysis with introducing swarm optimized ensemble learning algorithms for groundwater potentiality modelling in Asir region, Saudi Arabia, Geocarto International, DOI: $10.1080 / 10106049.2021 .1878291$

28. Mirarabi, A., Nassery, H.R., Nakhaei, M., Adamowski, J., Akbarzadeh, A.H., Alijani, F. (2019). Evaluation of data-driven models (SVR and ANN) for groundwater-level prediction in confined and unconfined systems. Environmental Earth Sciences, 78(15), 489.

29. MPO (Master Plan Organization) (1987) Groundwater resources of Bangladesh, Technical Report no 5. (Dhaka: Master Plan Organization) Hazra, USA; Sir M MacDonald, UK; Meta, USA; EPC, Bangladesh.

30. Pearson K., (1995) Contributions to mathematical theory of evolution: II. Skew variation in homogeneous material, Phil. Trans. Roy. Soc. London (A) 186, 343 - 414.

31. Rahman, ARMS, Hosono, T., Quilty, JM, Das, J., Basak, A., (2020) Multiscale groundwater level forecasting: Coupling new machine learning approaches with wavelet transforms. Advances in Water Resources, 141, 103595

32. Rashid, B., Islam, B., 2015. Drainage characteristics and evolution of the Barind tract, Bangladesh. Am. J. Earth Sci. 1 (4), 86.

33. Sahoo, S., Russo, T.A., Elliott, J., Foster, I., 2017. Machine learning algorithms for modeling groundwater level changes in agricultural regions of the US. Water Resour. Res. $53(5), 3878-3895$

34. Salam R, Islam ARMT, Pham QB, Dehghani M, Al Ansari N, Linh NTT (2020b) The optimal alternative for quantifying reference evapotranspiration in climatic sub-regions of Bangladesh, Scientific Reports, Sci Rep 10 (1), 20171.

35. Salam, R., Islam, A.R.M.T., Islam, S., 2020a. Spatiotemporal distribution and prediction of groundwater level linked to ENSO teleconnection indices in the North-western region of Bangladesh. Environment Development and Sustainability 22, 4509-4535.

36. Shahid S, Hazarika MK. 2010. Groundwater drought in the northwestern districts of Bangladesh. Water Resources Management, 24(10): 1989-2006. 
37. Shamsudduha, M.; Taylor, R.G.; Ahmed, K.M.; Zahid, A. (2011). The impact of intensive groundwater abstraction on recharge to a shallow regional aquifer system: Evidence from Bangladesh. Hydrogeol. J., 19, 901-916.

38. Sharafati, A., Asadollah, S.B.H.S., Neshat, A. (2020). A new artificial intelligence strategy for predicting the groundwater level over the Rafsanjan aquifer in Iran, Journal of Hydrology, 591, 125468

39. Sheikh Khozani, Z., Khosravi, K., Pham, B.T., Kløve, B., Wan Mohtar, W.H.M., Yaseen, Z.M., 2019b. Determination of compound channel apparent shear stress: application of novel data mining models. J. Hydroinf. 21, 798-811.

40. Shiri, J., Kisi, O., Yoon, H., Kazemi, M.H., Shiri, N., Poorrajabali, M., Karimi, S., 2020. Prediction of groundwater level variations in coastal aquifers with tide and rainfall effects using heuristic data driven models. ISH Journal of Hydraulic Engineering.

41. Šimůnek, J., N.J. Jarvis, M.Th . van Genuchten, and A. Gärdenäs. 2003. Review and comparison of models for describing non-equilibrium and preferential fl ow and transport in the vadose zone. J. Hydrol. 272:14-35

42. Song, Y., Zhou, H.,Wang,P.,Yang,M.,2019. Prediction of clathrate hydrate phase equilibria using gradient boosted regression trees and deep neural networks. J. Chem. Thermodyn.135, 86-96.

43. Tang, Q., Kurtz, W., Schilling, O.S., Brunner, P., Vereecken, H., Franssen, H.J.H., 2017. The influence of riverbed heterogeneity patterns on river-aquifer exchange fluxes under different connection regimes. J. Hydrol. 554, 383-396.

44. WARPO (Water Resources Planning Organization), 2000. National Water Management Plan. Volume 2: Main Report; Water Resources Planning Organization, Ministry of Water Resources: Dhaka, Bangladesh, 2000.

45. Wu, C., Zhang, X., Wang, W., et al., (2021) Groundwater level modeling framework by combining the wavelet transform with a long short-term memory data-driven model, Sci Total Environ, 783, 146948.

46. Wunsch, A., Liesch, T., Broda, S., 2018. Forecasting groundwater levels using nonlinear autoregressive networks with exogenous input (NARX). J. Hydrol. 567, 743-758. 
616

617

618

619

620

621

622
47. Yadav, B., Gupta, P.K., Patidar, N., Himanshu, S.K., (2020) Ensemble modelling framework for groundwater level prediction in urban areas of India, Sci Total Environ, 712, 135539.

48. Zinat MRM, Salam R, Badhan MA, Islam, ARMT (2020) Appraising drought hazard during Boro rice growing period in western Bangladesh, International Journal of Biometeorology, 64(10): 1697-1697. 